\title{
El tiempo histórico de La lucha por la vida (1904) de Pío Baroja: de una cronología lineal a una paradoja temporal
}

\author{
Historical Time in La lucha por la vida (1904) \\ by Pío Baroja: from a Lineal Chronology to a \\ Temporal Paradox
}

\begin{abstract}
Daniel Docampo Jorge
Universidad Nacional de Educación a Distancia (UNED) / Universidad de Navarra ddocampojorge@gmail.com ORCID iD: https://orcid.org/0000-0001-6009-0843
\end{abstract}

\section{RESUMEN}

El presente artículo discute la cronología histórica de la trilogía La lucha por la vida (1904) de Pío Baroja, que se ha establecido a través de numerosos indicadores temporales y de algunos acontecimientos históricos que entran en el hilo del relato. Como se tratará de demostrar, pese a existir una evolución temporal de los acontecimientos con la consiguiente evolución biológica de los personajes, el tiempo histórico no avanza y toda la trilogía se desarrolla en la misma época.

Palabras Clave: Pío Baroja; La busca; Mala hierba; Aurora roja; La lucha por la vida; cronología.

\section{ABSTRACT}

The present manuscript discusses the historical chronology of the trilogy La lucha por la vida (1904) by Pío Baroja, stablished using a number of time indicators and some historical events inside the narrative thread. As it will be demonstrated, despite existing a time evolution of the events with its consequent biological evolution of the characters, the historical time does not move forward and all the plot of the trilogy takes time in the same epoch frame.

Key words: Pío Baroja; La busca; Mala hierba; Aurora roja; La lucha por la vida; chronology. 


\section{LA LUCHA POR LA VIDA, UNA CRONOLOGÍA LINEAL}

La cronología de la trilogía de La lucha por la vida (1904) de Pío Baroja, compuesta por las novelas La busca, Mala hierba y Aurora roja, ha recibido la atención de críticos como Puértolas (1971), Beltrán de Heredia (1974), Alarcos (1982) y Ramsden (1982a y 1982b). Todos ellos, con algunas diferencias, han dividido la trilogía en tres épocas diferentes en función de diversas referencias temporales y apoyándose en algunos sucesos históricos, aparentemente dispuestos por Baroja para dotar de una linealidad más o menos rigurosa a toda la obra. Anteriormente, La busca había visto la luz como folletín en 1903 en las páginas del periódico El Globo, ampliando y redistribuyendo Baroja después su contenido para dar forma a las dos primeras novelas de la serie, lo que resultará clave para entender la cronología propuesta en este artículo.

Para Puértolas la trilogía abarca los años de 1885 a 1902. La busca comprendería el período de 1885 a 1888, Mala hierba el de 1892 a 1896 y Aurora roja el de 1900 a 1902. Para argumentar estas fechas, además de las referencias temporales, esta estudiosa toma como punto de partida la mención en Aurora roja de la coronación de Alfonso XIII, acaecida el 17 de mayo de 1902, y el reencuentro de Manuel y Juan dos años antes de este suceso y después de quince años sin verse tras la llegada de Manuel a Madrid, narrada al comienzo de La busca. Puértolas, por otro lado, registra un anacronismo en Mala hierba en la aparición del repatriado de Cuba que, según sus cálculos, aparece en mayo de 1895 pese a mencionar este que se había perdido la guerra, hecho ocurrido en 1898. Con todo, no duda en mencionar que: «[F]ijar la obra en el tiempo [es una] tarea que no resulta muy difícil, pues la trilogía posee una trabazón cronológica interna muy estricta, incluso sorprendente» $(1971,11)$.

Beltrán de Heredia adelanta tres años el comienzo de La busca a partir de una referencia velada -ya mencionada por Puértolas $(1971,74)$ - al famoso crimen de Fuencarral cuyo nombre trocó Baroja por el «célebre crimen de la calle de Malasaña» (Baroja 1998, 78) y que ya se encontraba en el folletón de El Globo como «el célebre crimen de la calle del Barquillo» (Baroja 1903, 6). Este cambio, asimismo, tendría repercusión en la figura del repatriado y en los años de separación de los dos hermanos:

[C]reo que merece considerarse, al comienzo de La busca, el relato del crimen de la calle Malasaña. Puesto que no ha habido ningún crimen destacado en esa calle y las circunstancias del que se decriben coinciden con el famoso de la calle de Fuencarral, hay que admitir que Baroja no ha hecho sino encubrir novelísticamente un suceso real. Debe situarse, por lo tanto, en el año 1888 el crimen de la calle de Malasaña y el comienzo de La busca. De esta manera, los dos hermanos habrían estado separados unos dieciocho años y el repatriado aparecería, justamente, en 1898 (1974, 151). 
Alarcos asume la modificación de Beltrán de Heredia y corrige algunos desajustes de Puértolas. Así, La busca comprendería los años de 1888 a 1891, Mala hierba de 1891 a 1896 y Aurora roja de 1900 a 1902. Sin embargo, según sus minuciosos cálculos, también existirían anacronismos de algunos acontecimientos históricos. Para este crítico, son cuatro los «acontecimientos reales fechables» $(1982,44)$ : el crimen de la calle Malasaña en La busca; la figura del repatriado y el debut de Chuchita -alusión a la figura real de la bailarina Consuelo Portela conocida, posteriormente, como La Chelito- en 1900, en Mala hierba; y, por último, la coronación de Alfonso XIII en 1902 en Aurora roja. De estos acontecimientos históricos, Alarcos indica la inexactitud en el relato de la pérdida de Cuba aparecida en 1895 y en el debut de Chuchita-La Chelito en 1896. Aceptando estos cálculos, la separación de Manuel y Juan quedaría determinada en doce años. Además, este crítico repara en los continuos descuidos en los que incurre Baroja a la hora de hilvanar las referencias temporales. Sin embargo, justifica estos desajustes como una concesión propia del territorio novelístico que no tiene por qué asumir la escrupulosidad de los libros de historia:

[L]a técnica temporal novelística no se ajusta a las mediciones precisas del calendario; en primer lugar, porque el escritor puede condensar mucho tiempo en pocas palabras, $y$, al revés, difundir en muchas páginas acontecimientos de poca duración. No es ello ninguna novedad. El tiempo astronómico y el tiempo psicológico no tienen la misma profundidad ni la misma intensidad. Por otra parte, aunque Baroja se apoye en hechos reales [...], el tiempo de la novela, por no ser historia, no tiene por qué ceñirse a una exactitud rigurosa (Alarcos 1982, 49).

Por último, Ramsden (1982b) apunta que la trilogía abarca los mismos años que defiende Puértolas. No obstante, los divide entre 1885-1888 para La busca, 1888-1893 para Mala hierba y 1900-1902 para Aurora roja. Este estudioso, además, repara en un mayor número de anacronismos derivados de la primera versión que Baroja hizo de La busca.

Así, por tanto, todos los críticos asumen que la trilogía de La lucha por la vida describe los avatares de la vida de Manuel Alcázar desde 1885 o 1888 hasta 1902 y, en palabras de Estruch (2012, XXXIII), a través de «referencias a sucesos o personajes de la época [...] muy escasas o imprecisas». Sin embargo, no se han tenido en cuenta otros acontecimientos históricos, objetivables todos ellos, que permitirían fechar con precisión la realidad en la que se mueven los personajes barojianos. 


\section{LA LUCHA POR LA VIDA, UNA PARADOJA TEMPORAL}

\subsection{La busca de El Globo (1903)}

La busca fue publicada por primera vez en el periódico El Globo entre el 4 de marzo y el 29 de mayo de 1903. Baroja ya había mostrado interés por estudiar el extrarradio madrileño y sus habitantes en algunos artículos como «Golfos» ( $L a$ voz de Guipúzcoa, 12 de abril de 1897), «El vago» (La voz de Guipúzcoa, 25 de diciembre de 1897), «Patología del golfo» (Revista Nueva, 15 de marzo de 1899), «Mala hierba» (El Globo, 12 de diciembre de 1902) o "Crónica. Hampa» (El Pueblo Vasco, 18 de septiembre de 1903). En «Gente de las afueras» se erigió como el precursor de la novela centrada en los suburbios:

Las afueras madrileñas no han producido gran curiosidad entre los escritores españoles.

Galdós tiene alguna nota descriptiva de las afueras madrileñas en la novela $\mathrm{Mi}$ sericordia; pero es la descripción del que se asoma a ver algo que no le produce interés.

[...] Las afueras de Madrid no han tenido escritor que las haya explorado y descrito. Únicamente yo he intentado hacerlo en las novelas La busca, Mala hierba y Aurora roja, novelas un tanto deshilvanadas, pero que tienen cierta autenticidad sentimental (Ahora, 5 de marzo de 1933, 5).

Sin embargo, a comienzos de siglo, un nuevo tipo de periodista, el reportero, más conocido con el anglicismo reporter (o, con tilde, repórter) — aunque el Diccionario de la Real Academia Española ya recogía reportero en su edición de 1899- también había puesto sus ojos en los suburbios desde periódicos como Heraldo de Madrid, ABC o Diario Universal en estudios monográficos que aparecieron en diferentes números, especialmente a partir de 1902. Desde sus reportajes se entiende la realidad madrileña a la que se refiere Baroja en La busca y es la misma que asumiría el lector de la época, preocupado por el incremento de la inseguridad y de la población que había de malvivir en condiciones extremas ${ }^{1}$

${ }^{1}$ El reporter se convirtió en una figura ineludible de la época, símbolo de la modernización de la prensa y, en muchas ocasiones, del sensacionalismo plagado de «inepcias, dislates, infundios y patrañas folletinescas» de los que habla Emilia Pardo Bazán al referirse a la prensa amarilla («Crónicas. La prensa amarilla», El Liberal, 11 de junio de 1898, 1). El comienzo de Nazarín $(1895 ; 2001,77-78)$ de Benito Pérez Galdós es significativo de cómo se le veía al definirle como «un periodista de los de nuevo cuño, de estos que designamos con el exótico nombre de repórter, de estos que corren tras de la información, como el galgo a los alcances de la liebre, y persiguen el incendio, la bronca, el suicidio, el crimen cómico o trágico, el hundimiento de un edificio y cuantos sucesos afectan al orden público y a la Justicia en tiempos comunes o a la higiene en días de epidemia». Y Madrid y sus afueras fueron un filón para este tipo de sucesos en los que el reportero no solo se quedó en la superficie sino que buscó detallar y contextualizar los ambientes sórdidos donde solían producirse. A lo largo de la última década del siglo XIX he localizado algunos artículos sobre el extrarradio y la vida de los 
golfos en Madrid - por ejemplo, «Los gitanos en Madrid» de Rodrigo en Heraldo de Madrid del 25 de octubre de 1893 o «Los albergues del crimen» de D. B. en Los Lunes de El Imparcial del 18 de junio de 1894-, pero es a partir de 1900 cuando empezaron a aumentar de manera considerable, seguramente por el auge de las teorías criminológicas (remito a la introducción de Maristany del Rayo en La mala vida en Madrid [XXXI-L]). Heraldo de Madrid dedicó numerosas columnas a describir la pobreza de la villa y sus afueras, sobre todo, desde la pluma de Aquiles Ullrich y Eduardo G. Gereda. Este último también se ocupó de las ilustraciones, tanto en sus reportajes como en los de Ullrich. Así, de Ullrich encontramos las siguientes crónicas: «Calor para los pobres» (29 de diciembre de 1901), «Las Cambroneras» (27 de febrero de 1902), «Barrio de los traperos» (19 de marzo de 1902), «Las Injurias» (15 de abril de 1902), «Rincones de Madrid. Notas de un reporter» (31 de octubre de 1902); y de Gereda: «Las echadoras de cartas» (1 de enero de 1903), «Las curanderas» (13 de enero 1903), «Una noche de invierno» (15 de enero de 1903), «El Palacio de Cristal» (11 de mayo de 1903), «La vida de los golfos» (30 de septiembre de 1903), «Las escuelas de los golfos» (6 de febrero de 1904). Gereda, además, colaboró para $A B C$ explorando la misma temática: «El barrio de los gitanos» (7 de julio de 1903), «El barrio de las Injurias» (31 de julio de 1903), «Las Carolinas» (4 de septiembre de 1903), «El Palacio de Cristal» (29 de septiembre de 1903) y «El Asilo del Norte» (10 de noviembre de 1903). También Constancio Bernaldo de Quirós y José María Llanas Aguilaniedo, autores del celebérrimo La mala vida en Madrid (1901), con varios puntos en común con La busca, dejaron en las columnas de la prensa artículos sobre los más desfavorecidos. El primero publicó en El Globo «Las habitaciones de los pobres» (3 de noviembre de 1902) y el segundo «Los golfos» (10 de noviembre de 1902) (Bernaldo de Quirós y Llanas Aguilaniedo 1998, 350-358). Por su parte, Diario Universal dedicó gran cantidad de reportajes a la vida madrileña, entre los que no faltaron los referidos a las clases más desfavorecidas: «Madrid íntimo» (5 de febrero de 1903), «El cementerio de los pobres» (1 de noviembre de 1903), «Las cigarreras» (7 de febrero de 1904), «La miseria en Madrid» (23 de marzo de 1904), «Las delegaciones de policía» (5 de julio de 1904) y «Plaga de mendigos» (22 de julio de 1904) de Carlos Crouselles; «El Asilo de Huérfanos» (21 de agosto de 1903) de E. Contreras y Camargo; «Los traperos» (7 de mayo de 1904) de Cristino Sánchez-Arévalo; «Los colilleros» (9 de diciembre de 1904) de P. Pito; o «La recogida de golfas» (8 de julio de 1905) de Bonifacio Chamorro. En este periódico, el oficio de reportero también fue materia de análisis en «El reporter» (27 de noviembre de 1905) de Carlos Martín Cortázar; y Antonio Sánchez Pérez en el cuento «El reportero» de Blanco y Negro (24 de agosto de 1901) se mofó de la fama que tenían estos periodistas de melodramatizar e inventar noticias sensacionalistas, lo que da una idea del interés y la novedad de su figura. El tema, por tanto, era cuestión palpitante de la época y el reportero de comienzos de siglo no perdió oportunidad de darlo a conocer. Aun así, este era consciente de lo inverosímil que podían resultar sus impresiones para quien no estuviera familiarizado con los suburbios, y periódicos como $A B C$ las acompañaban con abundantes fotografías. Todavía en 1903 se hablaba del extrarradio como algo sorprendente. Así, Juan del Puyuelo en «Madrid de noche» $(A B C, 22$ de enero de 1903, 3) apuntaba lo siguiente: «Nuestro deseo de informar al público de lo que no ve, nos ha llevado a algunas casas de los barrios bajos de Madrid, antros de la hampa madrileña, donde la máquina fotográfica puede reproducir cuadros espantosos que la pluma más galana del mundo no podría describir en toda su horrible realidad». El artículo se ilustraba con varias instantáneas donde se mostraba cómo dormían los golfos en la calle y que reflejan a la perfección las noches pasadas al raso por Manuel. Por otro lado, el Madrid desconocido se exhibía a los lectores no solo como algo curioso, sino para alertar de la figura del golfo y para debatir sobre los medios 
(Fig. 1). Andrenio, en una crítica a Mala hierba, ya mencionaba que "[1]o que sucede en [La busca y Mala hierba] no tiene nada de particular. A diario, en la sección de "Sucesos" de los periódicos tenemos los mismos casos en la novela referidos» («Revista literaria. Mala hierba [novela], por Pío Baroja [La lucha por la vida]», El Imparcial, 29 de mayo de 1904, 5). De igual forma Zeda, en su reseña a La busca de 1904, se dirigía al público contemporáneo:

Yo no he visitado los negros rincones en que Pío Baroja ha penetrado, y ha descrito después en su libro La busca; pero simplemente con recorrer las calles más céntricas de la Corte, he visto, como habrán visto todos mis lectores, enjambres de golfos descalzos y medio desnudos, buscando un poco de calor en torno de los hornos de asfalto; sé que hay, o había, un palacio de cristal, en donde se amontonaban por la noche, en repugnante promiscuidad, centenares de vagabundos; sé también que las cuevas de la Moncloa eran como un avispero de desgraciados, los cuales a veces quedaban enterrados en sus miserables agujeros («Lecturas de la semana. La busca. Novela, por Pío Baroja», La Época, 20 de febrero de 1904, 1).

Ramsden (1982b) ya señaló la contemporaneidad de la versión de 1903 en la que el lector de la época reconocería algunos hechos del pasado muy reciente. En este sentido, en la versión seriada se van entrelazando algunos indicadores del tiempo histórico en el que se mueve la acción, acompañados de una sucesión de referencias temporales que marcan el curso de los días. El men-

que debían tomarse para evitar su formación o para poder rehabilitarlo (no es casual que el reportero pudiera pertenecer, además, al ámbito sanitario como Gereda que era médico, al igual que Baroja, y Llanas Aguilaniedo farmacéutico; o al criminológico, como Bernaldo de Quirós). Las crónicas más descriptivas de la vida de lo que se llamó la golfemia se alternaron con artículos de honda reflexión. Por ejemplo, José Francos Rodríguez, director de Heraldo de Madrid, emprendió desde este periódico una campaña de concienciación sobre este problema solicitando la opinión de diversos especialistas en el tema recogida en varios artículos: «Mendigos y vagabundos. ¿Qué hacer con ellos?» (24 de mayo de 1903) de J. Piernas Hurtado; «El problema de la miseria en España» (27 de mayo de 1903) de E. Sanz y Escartín; «Mendigos y vagabundos. Escuelas-asilos» (1 de junio de 1903) de Emilio Sánchez Pastor; «Mendigos y vagabundos» (7 de junio de 1903) de Fermín H. Iglesias; «Vagancia y mendicidad. El trabajo como remedio» (7 de julio de 1903) de Alfonso Ruiz de Grijalba; «Mendigos y golfos» (2 de agosto de 1903) de Carlos Cañal (en este caso sobre la mendicidad en Sevilla). En algunos de estos artículos se razona acerca de la capacidad redentora del trabajo y de la función que había de realizar el Estado para inculcar esta idea en la sociedad. La trilogía barojiana se hace eco de esta tesis, ya que muestra la inconstancia laboral de Manuel en La busca y en Mala hierba. Ya en Aurora roja su reintegración en la sociedad se da por su actividad en la imprenta. Existe una idea romántica y una crítica implícita en esta reintegración pues se hace gracias al amor de la Salvadora y no por medio de las medidas gubernamentales. Sobre la realidad en la que se movió Baroja para escribir La lucha por la vida vid. Puértolas 1971; Moral Ruíz 2001; Marín Martínez, prólogos a La busca y Mala hierba (Baroja 2010a y 2010b) y Estruch 2012. Por otro lado, no hay que olvidar La horda (1905) de Blasco Ibáñez, que retrató los mismos lugares que Baroja y por lo que fue acusado de plagiario por el escritor vasco en «Gente de las afueras» (Ahora, 5 de marzo de 1933). 
cionado crítico (1982b, 14-18) calcula que la acción se desarrolla en un periodo de siete años entre 1895 y 1902. Sin embargo, aunque Baroja intercala marcadores temporales -mensuales, estacionales y biológicos ${ }^{2}$ - que hacen avanzar el relato, el tiempo histórico no lo hace de forma lineal y ordenada sino que oscila entre 1900 y 1902 o 1903. Estos desajustes cronológicos serán también muy habituales en La busca de 1904.

\subsubsection{Acontecimientos cercanos a $1903^{3}$}

El crimen de las Peñuelas

Cuando Manuel está comiendo en casa del señor Ignacio, situada en el Arroyo de Embajadores, se menciona el crimen de las Peñuelas (Baroja 1903, 8). En 1904, Baroja apostilló del citado crimen que «se trataba de un organillero celoso que había matado a su querida por una mala palabra» (Baroja 1998, 94).

Baroja se refiere a un crimen que tuvo eco en la mayoría de la prensa madrileña el 14 de mayo de 1902 y que fue calificado con titulares como «Crimen pasional» o «Crimen por celos». Los periódicos describieron ampliamente el asesinato de Pascuala a manos de su novio, Eugenio, conocido como el Pajarero, a causa de los flirteos de esta con José, un joven apodado el Torerito y que frecuentaba su casa, que estaba en el Arroyo de Embajadores, perteneciente al barrio de las Peñuelas, aun con Eugenio en ella. Lo que no deja de ser una historia frecuente en sucesos de este tipo sirvió, además, a Baroja para relatar el asesinato de Milagros a manos de Leandro al escuchar que prefería

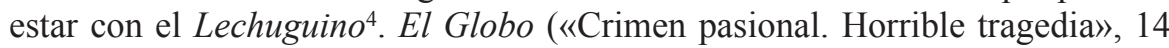
de mayo de 1902, 3) cuenta de esta manera el suceso:

A las seis de la tarde se hallaban, como de costumbre, en casa de Pascuala, esta y su novio, acompañados por el Torerito, la madre y dos hermanos de la joven.

${ }^{2}$ Dos veces se menciona la edad de Manuel: quince años (Baroja 1903, 19) y diecisiete (Baroja 1903, 32). Baroja lo modificó en Mala hierba y Manuel dice tener dieciocho (Baroja 1998, 263) y veintiuno (Baroja 1998, 409). Alarcos, en su minucioso estudio de marcadores temporales, señala que no se cumple la cronología entre los dieciocho y los veintiuno y sentencia que «no deben extrañarnos estas inexactitudes cronológicas» $(1982,47)$.

${ }^{3}$ Ramsden (1982a, 21-22 y 1982b, 19-20) indica la cronología del derribo del palacio de Osuna, el asfaltado de la puerta del Sol y el derribo de las cuevas de la Montaña. Sobre don Tancredo apunta que difícilmente pudo estar activo en la década de los 80 del siglo XIX. Por otro lado, expongo los sucesos de este apartado (como en el resto) en orden de aparición en la novela.

${ }^{4}$ He revisado los diarios de las décadas de 1880 y 1890 buscando algún famoso crimen más en las Peñuelas motivado por los celos y no he localizado ninguno. La contemporaneidad del texto y su parecido con la historia de Leandro y Milagros es más que significativa para asumir este crimen como el aludido por Baroja. 
El tema de la conversación entre los novios era, como siempre, los celos de él... Las cosas no podían seguir así; él sufría mucho, mucho... ¿No decía ella que le quería? Pues, ¿por qué atendía al otro? Era preciso acabar de una vez...

Como todas las tardes, decidieron los amantes salir a paseo, y así lo hicieron, siendo seguidos por el Torerito.

Esto exasperó a Eugenio de tal modo, que estos, ya en la calle, y a pocos pasos de la casa, exclamó dirigiéndose a Pascuala:

-Esto se ha terminado; o él o yo. ¡Elige entre los dos!

-Pues bien; él -contestó ella resueltamente. Entonces el Pajarero sacó un cuchillo de grandes dimensiones, y abalanzándose sobre la joven la descargó una puñalada en el pecho.

La lesionada quiso huir, dando un terrible grito, que llegando hasta la casa hizo salir a la madre y a los hermanos de la joven, al tiempo que el agresor asestaba una segunda puñalada a la ya lesionada joven, en la espalda.

Abalanzóse la madre sobre el criminal; pero haciendo este nuevamente uso de arma, causóla también una herida, dándose a la fuga inmediatamente, perseguido por los hermanos de la joven.

Ya iban a darle alcance, cuando le vieron caer al suelo, después de asestarse varios golpes en el costado con el mismo cuchillo.

La confusión que se produjo fue indescriptible.

Las dos mujeres fueron conducidas a la Casa de Socorro sucursal de la Inclusa, a donde poco después era llevado también el autor del hecho.

Las versiones entre periódicos difieren en algunos detalles. El País del mismo día («Horrible crimen. Asesino y suicida», 14 de mayo de 1902, 2), por ejemplo, detalla que la relación de Pascuala y Eugenio se había enfriado y la asesinada había empezado a sentir predilección por el Torerito. Los dos hombres decidieron ir a casa de Pascuala y ponerse delante de ella para que eligiera entre uno de los dos. Así lo hicieron y ante la pregunta que formuló el Torerito - «¿A cuál de los dos quieres, Pascuala?»- que se resolvió de forma negativa para Eugenio, se desencadenó la tragedia. Sin embargo, este diario no indica que la víctima tuviese hermanos, siendo perseguido por el público que vio la escena hasta que, al ser detenido por un guardia en la calle de Moratines, se asestó varias puñaladas en el tórax ${ }^{5}$. El Liberal («Crimen pasional. Dos muertos y un herido», 14 de mayo de 1902, 3), por su parte, relata que se apuñaló antes de ser detenido: «A las voces acudió el guardia de orden público número 836 y, al verle el agresor, comenzó a herirse, dándose hasta cinco puñaladas en el pecho. El guardia intentó arrebatarle el arma, pero Eugenio se resistió hasta que, falto de fuerzas, cayó al suelo».

Los diarios indican que Eugenio ejercía de albañil, pero en la versión final de 1904, Baroja añade que era organillero, quizás por la mala fama que estos tenían y por no recordar, seguramente, la profesión del agresor al reescribir el

\footnotetext{
${ }^{5}$ Unos periódicos señalaban que se acuchilló en el costado, como Leandro, y otros en el pecho.
} 
pasaje posteriormente ${ }^{6}$. En todo caso, la comparación con el texto de La busca resulta esclarecedora ya que la historia tiene importantes puntos en común. Así, en la relación deteriorada de Milagros y Leandro aparece el Lechuguino. Esta acaba por dejar a Leandro y se promete con el Lechuguino, lo que provoca la ira de Leandro, cuya reacción se describe en boca de dos testigos:

-Estaba yo aquí leyendo el periódico - contó el viejo prendero- y la señora Ramona y su hija en la galería hablando con el Lechuguino. Estaban ellos de broma, cuando entró Leandro, se acercó a la puerta de su casa, la abrió y volviéndose después, de repente, la dice a la Milagros:

$-¿$ Es ese tu novio?

-Sí -contestó ella.

-Bueno, pues yo vengo aquí a concluir de una vez, gritó él, que estaba pálido como un muerto. ¿A cual de los dos quieres, a él, o a mí?

-A él -chilló la Milagros.

-Entonces se acabó todo - gritó Leandro con una voz ronca; voy a matarte ${ }^{7}$. Luego yo ya no me di cuenta de nada; antes que me pudiera acercar, la muchacha estaba en el suelo, echando sangre por la boca; la madre empezó a gritar y Leandro echó a correr escaleras abajo detrás del Lechuguino.

[...] -Pues yo le vi cuando se mató - dijo un chiquillo-; íbamos corriendo todos detrás de él, gritando: ¡A ese! ¡A ese! Cuando aparecieron por la calle del Amparo dos guardias, sacaron el sable y se pusieron delante de él; [...] Entonces no se vio más que a Leandro, que se metía y se sacaba la navaja por el costado. Cuando uno de los guardias le agarró el brazo y le sacó el cuchillo se cayó como un saco (Baroja 1903, 18; la narración de 1904 es muy similar [Baroja 1998,153-154]) ${ }^{8}$.

${ }^{6}$ Gutiérrez Abascal, bajo el pseudónimo de Kasabal, refiere en el artículo «Microbios morales» que: "Crímenes y escándalos han ido unidos en los días pasados a la figura repugnante del organillero, haciéndola más odiosa y justificando el recelo con que las gentes honradas ven hacerse dueños de las calles a esos representantes del hampa, que salen de la hez de la golfería» (Heraldo de Madrid, 10 de mayo de 1904, 1). Estruch (Baroja 2012, 64, nota 13) apunta a un crimen que apareció en algunos periódicos como El Imparcial o El Globo el 18 de junio de 1903 donde un carpintero -que también trabajaba como organillero- mató por celos a su novia en la calle Fernando el Católico tras una contestación de esta que le enloqueció. Sin embargo, la mención del crimen en la primera versión de La busca, su parecido con la historia de Leandro y Milagros y el enclave real del suceso en el barrio de las Peñuelas hace más factible que aluda al hecho de 1902. En este sentido, y como explico en la nota 31, Baroja únicamente noveliza el crimen de Fuencarral. Por otro lado, no comparto el análisis de Ceballos Viro (2016) que lee el episodio de la kermesse y el crimen de Leandro como una reinterpretación de La verbena de la Paloma. Como he indicado, la historia se basa en la noticia periodística por mí referida y la kermesse no deja de ser un enclave castizo y muy popular de la época.

7 En El Día («Crimen pasional. Dos muertos y un herido», 14 de mayo de 1902, 2), se reproduce un diálogo entre Eugenio y Pascuala en el que, poco antes del crimen, este le dice: «Pues yo también te voy a matar a ti».

${ }^{8}$ En la versión de 1903 no se encuentra la escena melodramática propia de la novela de folletín, tan del gusto de Baroja, en la que el forense descubre el medallón que tiene en 


\section{Don Tancredo}

En el Corralón, el narrador alude a la suerte de don Tancredo a la que juegan los niños para pasar el tiempo:

Los chicos pequeños se divertían jugando al toro. Una de las suertes más aplaudidas era la de don Trancredo. Se ponía un chico a cuatro patas y otro que fuera más pequeño y no pesase mucho, encima. La actitud de este era un pie adelante, el cuerpo echado hacia atrás, los brazos cruzados y cabeza, con un sombrero de papel, alta y erguida.

Se acercaba el toro, mugía, olfateaba a don Trancredo y pasaba junto a él sin derribarle. Entonces don Tancredo bajaba de su vivo pedestal a recibir el aplauso del público. Algunas veces al toro se le ocurría tirar estatua y pedestal al suelo y caían los dos entre los gritos del público (Baroja 1903, 10).

Esta suerte del toreo fue ejecutada por primera vez en España por un novillero valenciano llamado Tancredo López Martín en 1899 que, todo de blanco, permanecía quieto subido a un pedestal en el centro del ruedo a la espera del toro que giraba varias veces a su alrededor, confundiéndolo con una estatua de mármol o de piedra. Presentado como «El rey del valor» paseó su espectáculo con gran éxito por todo el país e, incluso, tuvo imitadores (e imitadoras), popularizándose el término tancredismo para todo lo relacionado con su persona. Más adelante, se vuelve a mencionar dibujado por Perico Rebolledo en una callejuela de la Corrala (Baroja 1903, 11). Tal fue la fama de don Tancredo que, como menciona Baroja (1997b, 695), fue interpretado por un cómico en el teatro (no se refiere al disparate cómico-lírico La estatua de don Tancredo [1905]) y ha pasado al lenguaje coloquial con el significado de 'indeferentismo'; y, justamente, ya en la época se caricaturizaba así al gobierno de Práxedes Mateo Sagasta («El acta de Cabra», La Correspondencia Militar, 1 de julio de 1901; «Couplet liberal», La Correspondencia Militar, 23 de octubre de 1902) $)^{9}$.

\section{El derribo del palacio de Osuna}

En su peregrinar por las calles de Madrid, Manuel ve que «[e]staban comenzando a derribar el antiguo palacio de Osuna, y [...] se puso a contemplar

el pecho Milagros con el retrato de Leandro. Zeda calificó como «hermosa» esta adición en su reseña a La busca («Lecturas de la semana. La busca. Novela, por Pío Baroja», La Épo$c a, 20$ de febrero de 1904, 1).

9 En Aurora roja también se nombra a don Tancredo (Baroja 1998, 599-600). La prensa se ocupó en numerosas ocasiones de la figura de este novillero. Sirvan de ejemplo dos artículos de Nuevo Mundo, ambos titulados «Don Tancredo», de Zeda (6 de febrero de 1901) y Enrique Sa del Rey (27 de agosto de 1903). 
cómo iban cayendo pedazos de cascote a los golpes de la piqueta de los obreros» (Baroja 1903, 20). Ramsden (1982b, 19-20) da un intervalo de años para este suceso entre 1899 y 1901 pero, realmente, comenzó a mediados de $1900^{10}$.

El campanil de la basílica de Atocha

Cerca del cuartel de María Cristina «se veía en frente la torre blanca, recién construida, de Atocha y la antigua iglesia adosada a ella, desmantelada, con el tejado roñoso, de color sangriento, con aberturas en algunos sitios, por donde se veían maderos negruzcos y rotos» (Baroja 1903, 22).

El proyecto del arquitecto Fernando Arbós para la construcción de la nueva basílica de Nuestra Señora de Atocha se aprobó en 1891 y no llegó a terminarse nunca. Después de diez años de obras con numerosos parones por falta de presupuesto, se finalizaron únicamente la torre campanario y el panteón. Este último se inauguró en 1901 pero el campanil ya estaba acabado en $1900^{11}$.

\section{El asfaltado de la Puerta del Sol}

En la mitad del folletín, se advierte que «[e]staban asfaltando un trozo de la Puerta del Sol» (Baroja 1903, 30). Como ya señaló Ramsden (1982b, 19) este acontecimiento ocurrió en 1900. De hecho, Baroja publicó en El País del 17 de septiembre de ese año el artículo «Humo» donde habla de forma muy parecida sobre las labores de asfaltado, aunque equiparándolas de forma pesimista al cambio político y social de la realidad española ${ }^{12}$.

${ }^{10}$ La primera mención a la demolición del palacio la he localizado en La Correspondencia de España del 6 de julio de 1900 donde se informa, en la sección de anuncios, de la venta de los materiales del derribo. Se extendió, al menos, hasta septiembre de ese año según La Época, que refiere el día 6 de ese mes el accidente de un operario que trabajaba en dicha obra («Sucesos de Madrid. Caída»).

11 En La Época del 21 de mayo de 1900 («El reloj de la nueva Real basílica de Atocha») se indica que ya está terminada la torre a falta de la instalación de un reloj de grandes dimensiones. En el Boletín de la Sociedad Española de Excursiones del 1 de diciembre de 1900 ( «Visita a las obras de Nuestra Señora de Atocha»), se describe la visita a las obras de la basílica el 19 de noviembre con el reloj ya instalado. La imagen de la torre con los andamios fue una estampa habitual en Madrid durante largo tiempo: en La Revista Moderna del 19 de noviembre de 1898 y en Blanco y Negro del 7 de abril de 1900 se muestran fotografías de la torre con las plataformas de construcción. De ahí que Baroja no tuviera dudas al señalar su reciente finalización.

12 En Nuevo Mundo del 17 de octubre de 1900 se incluye el amplio reportaje «La Puerta del Sol», firmado por Florete, con fotografías y dibujos sobre el asfaltado de la Puerta del Sol que corrobora lo expuesto por Baroja. Ricardo, el hermano Pío, realizó en 1900 un grabado titulado Asfaltadores en la Puerta del Sol. 
El derribo de las cuevas de la Montaña

Cuando Manuel se encuentra con el Bizco en la Puerta de Sol, este le dice que está ahí porque «[n]os han derribado las cuevas de la Montaña» (Baroja 1903, 30). A finales de agosto y principios de septiembre de 1901 se anunciaba en diferentes periódicos el derribo de las cuevas de la Montaña. El Globo del 31 de agosto de 1901 recogía así noticia:

Se ha dispuesto por la Alcaldía, y de acuerdo con el capitán general, que las fuerzas de zapadores minadores destruyan las cuevas que existen en la Montaña del Príncipe Pío, debajo del cuartel del mismo nombre, y que son albergue, desde tiempo inmemorial, de golfos, de «randas» y de mujerotas de la peor especie («Municipales. Otros asuntos», 2).

No he localizado ninguna noticia que narrara el momento del despido de los habitantes de las cuevas pero El Imparcial del 18 de octubre de ese año recoge que: «En la montaña del Príncipe Pío, los obreros municipales, auxiliados por los soldados de la brigada de zapadores, están convirtiendo los terraplenes en paseos circulares, y haciendo las plantaciones de pinos» («Notas municipales. Otras reformas», 2). La noticia del derribo fue muy comentada en los periódicos y algunos de ellos alertaron acerca de la inutilidad de esta acción si no iba acompañada de una reeducación social del golfo ${ }^{13}$.

\section{La recogida de pobres al Cerro del Pimiento}

Un residente del Asilo de las Delicias refiere su historia a Jesús y a Manuel. Después de vagabundear por Madrid con su hijo cuenta cómo pidió a un guardia que le llevara a un asilo. Este le dijo que para ello tendría que verle pidiendo limosna, pero el residente se resistió, por lo que el guardia le recomendó ir al Asilo de las Delicias. Ante esto, le explicó otro residente que «si le llegan a coger no adelanta usted nada [pues] le hubieran llevado al Cerro del Pimiento y allá se hubiese usted pasado el día sin probar la gracia de Dios» (Baroja 1903, 47).

El Hospital del Cerro del Pimiento, también conocido como Hospital de Epidemias, se construyó entre 1885 y $1899^{14}$. Aunque estaba destinado a tratar

${ }^{13}$ Así, por ejemplo, en El Imparcial desde la columna «Grave problema social. La guerra al golfo» del 2 de septiembre de 1901, que continuó los días 7, 13 y 24 de ese mes; R. M. en «Los golfos» de La Correspondencia militar del 2 de septiembre de 1901; Zeda en «La protección al niño» de La Época del 5 de septiembre de 1901; Mariano de Cavia en «El suspiro del golfo» de El Imparcial del 5 de septiembre de 1901; y Mundano en «Madrid» de Nuevo Mundo del 9 de septiembre de 1901.

${ }^{14}$ Como señala Sa del Rey en «El tifus en Madrid» (Nuevo Mundo, 13 de mayo de 1903, 15): «[F]ue empezado a construir cuando el cólera de 1885 y abandonaron las obras hasta que hace pocos años, ante los temores de invasión de peste bubónica, a toda prisa se 
enfermedades epidémicas, a partir de abril de 1901 se dio la orden de que algunos pabellones se utilizaran para dar cobijo a los mendigos. Como recoge $E l$ Globo («Informaciones municipales. Para los pobres», 10 de abril de 1901, 1): «Al gobernador civil y al alcalde se comunicó ayer el acuerdo de la Comisión provincial cediendo temporalmente al Ayuntamiento, y con destino a albergar a los pobres que se recojan en la vía pública, los pabellones hospitalarios del Cerro del Pimiento».

Como se desprende de las palabras del residente, no debía de gozar de buena fama, al menos en 1901. Así lo denuncia El Liberal («Noticias», 12 de septiembre de 1901, 3):

Un exsocio de la Asociación Matritense de la Caridad nos denuncia varios abusos que se cometen con los mendigos recogidos en los pabellones hospitalarios del cerro del Pimiento.

Se les maltrata de palabra y de obra; se les despoja del poco dinero que tienen; se ven sometidos a la autoridad, de quien no sabe ejercerla con discreción.

\section{El repatriado de Cuba}

La figura del repatriado de Cuba ha sido estudiada cronológicamente por todos los críticos respecto de La busca de 1904. Como se ha señalado anteriormente, para Puértolas $(1971,12)$ aparece en 1895 pese a mencionarse la pérdida de la isla ${ }^{15}$; Beltrán de Heredia cuadró la fecha a 1898 (1974, 151); y Alarcos $(1982,48)$ la volvió a retrasar a 1895. Ramsden $(1982 a, 19)$ anota que su aparición debía darse, como mínimo, en 1899 al comentar el repatriado en Mala hierba que había sobrevivido al invierno anterior, encontrándose la acción en mayo -de abril en la versión 1903-. En realidad, que Baroja califique a este personaje como «repatriado», no implica que deba aparecer necesariamente en 1898 o 1899. Las noticias en la prensa designaban de esta manera a los soldados que habían participado en la guerra de Cuba más allá de esos años. Por ejemplo, en El País del 17 de febrero de 1902 se lamentan de una vieja problemática sobre la retribución de los repatriados, considerada una de las causas de su pobreza:

Constantemente llegan a nuestra Redacción quejas de los repatriados de Cuba, cuyos haberes, a pesar de estar liquidados, no consiguen hacerlos efectivos.

\footnotetext{
puso término al Hospital». Heraldo de Madrid del 3 de septiembre de 1899 («El Hospital de Epidemias») habla ya de la edificación como una obra terminada.

${ }_{15}$ El repatriado cuenta a Manuel los desdenes que tuvo que aguantar a su llegada a la Península. Entre ellos, recuerda una frase que le espetaron: «Si hubierais tenido riñones no se hubiera perdido la isla» (Baroja 1903, 50).
} 
Son tantas ya las veces que nos hemos interesado por la suerte de estos infortunados, que consideramos tan inútiles nuestras quejas como las suyas.

Tiempo perdido («Noticias», 3$)^{16}$.

También El Siglo futuro del 17 de marzo de 1903 refiere el suceso de un asalto en un hotel de Madrid donde el ladrón fue reducido con la ayuda «[d]el sobrino del portero, un repatriado de Cuba» («La seguridad en Madrid. Asalto de un hotel», 1).

En La busca se mencionan algunos acontecimientos más de la guerra de Cuba como la alusión al héroe de Cascorro (Baroja 1903, 45) o a «la guerra de exterminio decretada por el bandido de Weyler» (Baroja 1903, 50) ${ }^{17}$.

\subsubsection{Otros acontecimientos}

En esta primitiva versión de 1903, además, existen otros acontecimientos fechables que están detrás del momento de la acción y que merece la pena anotar por su posterior contraste con la trilogía de $1904^{18}$.

\section{De Soria a Madrid}

En su viaje en tren a Madrid, Manuel sale del apeadero de Soria, pasa por Almazán donde hace escala una hora y llega a la estación de Alcuneza donde vuelve a hacer una escala de varias horas (Baroja 1903, 4). De ahí fue a Madrid directamente. Como observó Ramsden, la línea de Soria a Madrid, con enlace en Alcuneza, se dio por finalizada en el verano de $1892^{19}$.

\section{La Doctrina}

La Asociación del Apostolado del Corazón de Jesús y San Ignacio de Loyola estaba formada por mujeres de la alta sociedad y era conocida como la Doc-

${ }^{16}$ El País de aquella época tiene varios artículos preocupándose por los haberes de los repatriados. Moral Ruíz (1972) estudió muy atinadamente la figura del repatriado y su situación de desamparo en España.

17 En octubre de 1896, en Cascorro (Cuba), Eloy Gonzalo incendió, jugándose la vida, la casa donde estaban atrincherados los insurgentes cubanos que estaban asediando el derruido fuerte donde se encontraban los soldados españoles, en número muy inferior y en condiciones penosas tanto médicas como alimentarias. Se le llamó «el héroe de Cascorro» y se le erigió una estatua en junio de 1902 en la plaza del Rastro (hoy plaza de Cascorro); por otro lado, Valeriano Weyler relevó al general Martínez Campos como capitán general de Cuba, puesto que ejerció desde enero de 1896 a octubre de 1897.

18 Todas las referencias de este apartado excepto la Doctrina, el héroe de Cascorro y el Asilo de las Delicias ya han sido analizadas por Ramsden (1982a, 19-22). Omitiré, en la medida de lo posible, las referencias a las páginas de este crítico en este apartado por no sobrecargar el texto.

19 Concretamente el 1 de julio («Las provincias», La Época, 5 de julio de 1892). 
trina. Desde 1885 se dedicaba a enseñar el catecismo y a auxiliar a los más desfavorecidos de Madrid (vid. «Diario eclesiástico», El Correo Español, 17 de mayo de 1895, 2). En La busca de 1904 se indica que, para llegar al lugar en el que se encontraba la Asociación, los pobres «entraban por el puente de Toledo y seguían por el camino alto de San Isidro a detenerse ante una casa roja [...] que tenía un patio con una figura de Cristo en medio» (Baroja 1998, 105). En la versión de El Globo, que sigue aludiendo al puente de Toledo y al camino alto de San Isidro, existe alguna diferencia que, además, ubica con más precisión el lugar: «[Los pobres] se detenían ante un edificio de ladrillo que estaba frente al cementerio de Santa María, con un patio grande plantado de acacias, en medio del cual había un Cristo de mármol blanco» (Baroja 1903, 12).

Sin embargo, al menos hasta finales de 1894, la Asociación no contaba con el citado edificio para realizar su labor social, aunque a mediados de ese año se anunció su construcción en La Correspondencia de España («Obra piadosa», 25 de julio de 1894, 2):

La asociación del Apostolado del Corazón de Jesús y San Ignacio de Loyola, que hasta ahora venía ejerciendo al aire libre en la pradera del Canal su misión de instruir en doctrina cristiana y en los deberes religiosos a los numerosos adultos de ambos sexos inscriptos en la Catequesis de la Asociación, podrán verificarlo dentro de algunos meses, en la capilla y salones que van a edificarse en término de la parroquia de San Pedro, pasando el puente de Toledo, a la derecha del camino que conduce al cementerio de San Isidro.

Allí una piadosa asociada ha comprado un extenso solar para este objeto y con toda solemnidad que la iglesia tiene establecido para estos casos, se ha bendecido y colocado ya la primera piedra de la capilla, que será de sólida construcción y bastante capaz y a cuyos lados se edificarán también dos grandes pabellones, uno para hombres y otro para mujeres, donde se instruirá y moralizará a los vecinos de aquellos barrios. El autor de los planos y de dirigir las obras es el caritativo señor marqués de Cubas, y la capilla [tendrá] en su parte más culminante una imagen del Sagrado Corazón de Jesús.

El cementerio de Santa María al que alude Baroja estaba al lado del camino alto de San Isidro, muy cerca del cementerio del mismo nombre. No he podido localizar ninguna noticia sobre la inauguración del edificio: en octubre de 1894, indica José María Cos y Macho («Contra la libertad de cultos», La Unión Católica, 12 de octubre de 1894, 1) que todavía seguían predicando «al aire libre, sin asientos y sin más amparo ni abrigo que la bóveda de los cielos» y no es hasta el 13 mayo de 1896 en El Movimiento Católico cuando he podido constatar una alusión a dicha edificación: «La capilla que días pasados fue robada en el camino alto de San Isidro pertenece a la Asociación del Apostolado del Sagrado Corazón de Jesús y San Ignacio de Loyola» («Noticias generales», 2) ${ }^{20}$.

${ }^{20}$ El episodio de la Doctrina de La busca de 1904 fue reproducido por El País el 10 de abril de 1904 con una breve introducción que ensalzaba la trilogía barojiana. Froilán León 


\section{El automóvil en España}

Don Alonso, conocido como el Titiritero (y como el Hombre-Boa en la versión de 1904) relata a los habitantes de la Corrala varias historias acerca de su periplo como acróbata fuera de España. Una de ellas refiere el ataque de un cangrejo gigante que «hacía fa... fa... fa..., como un automóvil» (Baroja 1903, 14). Más adelante, Manuel ve en la Puerta del Sol cómo «[c]ruzaban [...] coches, automóviles, caballos, carros» (Baroja 1903, 30).

Como señala Ramsden (1982a, 22): «[C]ar production hardly developed before 1897 and the first cars appeared in Spain at some time between 1897 and $1900^{21} \gg$.

\section{Las zarzuelas de la kermesse}

En la kermesse de la calle de la Pasión ${ }^{22}$ a la que van Leandro y Manuel tocaron «el shotis de Los cocineros» (Baroja 1903, 16) y «el paso doble [sic] de El tambor de granaderos» (Baroja 1903, 16). El tambor de granaderos, con libreto de Emilio Sánchez Pastor y música de Ruperto Chapí, se estrenó en el Teatro Eslava de Madrid el 16 de noviembre de 1894; y Los cocineros, con letra de Enrique García Álvarez y Antonio Paso y música de Joaquín Valverde Sanjuán y Tomás López Torregrosa, lo hizo en el mismo teatro el 6 de marzo de 1897.

\section{El cuartel de María Cristina}

El Expósito cuenta a Manuel que va al cuartel de María Cristina a por el rancho que dan a los más necesitados (Baroja 1903, 22). Ramsden fecha este edificio entre 1892 y 1895 pero fue finalizado sobre septiembre de $1893^{23}$.

en La Lectura Dominical del 17 de abril de ese año («Sección obrera. La Doctrina»), arremetió duramente contra la visión que daba Baroja de la mencionada asociación benéfica.

21 Traduzco: «La producción de automóviles apenas se desarrolló antes de 1897 y los primeros automóviles aparecieron en España en algún momento entre 1897 y 1900». Aún el 25 de agosto de 1899, la revista ilustrada Alrededor del mundo lamentaba que, debido al mal estado de los caminos, «[e]n España los coches mecánicos no han alcanzado todavía gran éxito porque es punto menos que imposible su uso fuera de Navarra y de las provincias del Norte» («Los progresos de los automóviles», 8). Respecto al Titiritero, Ramsden (1982a, 20) señaló la modernidad de los objetos que le caracterizaban -el fonógrafo y el juego con la torre Eiffel- y en La busca de 1904 los consideró anacrónicos.

${ }^{22}$ La kermesse de la calle de la Pasión se empezó a celebrar en 1891 (Ceballos Viro 2016, 243) y se organizó durante años en el solar número 16 de dicha calle. Se hacía en agosto, en la Verbena de San Cayetano, y tenía una finalidad benéfica.

${ }^{23}$ La Iberia del 17 de septiembre de 1893 indica que «[e]ste nuevo edificio militar ha sido construido con todas las comodidades, y reúne todas las condiciones higiénicas que en los modernos tiempos exige el acuartelamiento de las tropas» («Noticias», 3). El 8 de octu- 


\section{El Asilo de las Delicias}

Manuel y Jesús van a pasar la noche en el Asilo de las Delicias que «estaba en la calle de Méndez Álvaro» (Baroja 1903, 46; esta puntualización desaparece en Mala hierba). A continuación sigue la decripción del lugar:

[C]omo no se hallaba abierto aún, [Manuel y Jesús] fueron a pasear por el antiguo camino de Yeseros y se internaron por los campos yermos, en los que solo se veían casuchas miserables [...].

Volvieron al anochecer. El Asilo estaba a la derecha del camino de Yeseros, marchando de Madrid, no muy lejos de unos cuantos cementerios abandonados. Había sido, indudablemente, en otro tiempo la casa de algún rico; tenía aspecto de chalet suizo, con el tejado puntiagudo, y conservaba galerías y escalinatas de madera. En el balcón del chalet había un letrero donde ponía: «Asilo Municipal del Sur», y sujeto al barandado un farol de cristal rojo lanzaba su luz sangrienta en medio de aquellos campos desiertos (Baroja 1903, 46).

Este asilo fue inaugurado el 24 de diciembre de 1898 en la calle Méndez Álvaro, número 24 (vid. «Noticias», El Liberal, 24 de diciembre de 1898, 2) ${ }^{24}$. Roberto de Palacio en «El frío y los pobres» de Alrededor del Mundo (2 de enero de 1902) mostró las interioridades de los asilos de Madrid, entre los que estaba el referido por Baroja:

El asilo del Sur está en la calle de Méndez Álvaro. Es sin duda el que mejores condiciones reúne para el fin a que esta dedicado. La casa es un chalet de fábrica y madera de agradable aspecto, donde habitaba su primitivo dueño el Sr. Ureña. El chalet tiene tres pisos: en el bajo están los dormitorios para los asilados, así como en parte del principal, y en el segundo se halla la vivienda del encargado del asilo. [...] El asilo está abierto de Diciembre a Junio (7-8) (Fig. 2).

Se apostilla, además, en la narración barojiana que «[1]a primera vez que fueron al Asilo de las Delicias, fue una tarde de Febrero» (Baroja 1903, 46), por lo que, como mínimo, la acción debería situarse en 1899.

Con todos estos datos, puede asegurarse, sin lugar a dudas, la contemporaneidad de la versión de 1903. En sus memorias, Baroja no es lo suficientemente exacto a la hora de recordar cuándo comenzó a recoger datos para escribir

bre de ese año, Heraldo de Madrid le dedicó el artículo «Actualidad. Cuartel de María Cristina», con dibujo incluido, dándolo por terminado.

${ }^{24}$ La Época del 27 de diciembre de 1898 se ocupa de este albergue en «El asilo de la noche» que describe la zona de forma parecida a la de Baroja, ubicándolo en las afueras de Madrid y cerca del antiguo cementerio de San Nicolás. Bernaldo de Quirós se refiere a él en un artículo que no he visto referenciado en ninguna publicación y que lleva por título «El quinto estado social. Norte y sur» en Heraldo de Madrid del 4 de diciembre de 1902. 
La busca, que supone en 1902 o un poco antes ${ }^{25}$. Sin embargo, dados los acontecimientos fechados en 1900, como el derribo del palacio de Osuna, la finalización del campanil de la basílica de Atocha y el asfaltado de la Puerta del Sol es posible conjeturar que Baroja comenzó a bosquejar La busca en ese año.

\subsection{La busca (1904)}

Baroja reelaboró y amplió significativamente la versión seriada de 1903 dividiéndola en La busca y Mala hierba, publicadas en 1904. Ramsden (1982b, 13-22) comparó la novela de 1903 con las de 1904 y observó que la reescritura en forma de libro de las dos primeras entregas de la trilogía y la redacción de Aurora roja implicó un cambio en la perspectiva temporal que obligó a Baroja a modificar ciertos hitos próximos a 1903 para adaptarlos a la nueva cronología que retrasaba en quince años el comienzo de la novela. Esto, no obstante, supuso la aparición de distintos anacronismos que desvirtuaban la veracidad cronológica y que, como sugiere Ramsden, Baroja intentó paliar: «Baroja's general aim in the 1903-04 revision appears to have been to maintain, and even to increase, the overall chronological verisimilitude of the work $^{26}{ }_{\gg}(1982 \mathrm{~b}, 18)$.

Sin embargo, como se tratará de demostrar, la relación de datos y acontecimientos presentes en La busca de 1904 hacen incoherente el fechado que se ha venido aceptando hasta ahora. El problema ha surgido por la búsqueda de una consistencia cronológica por parte de los críticos que no pareció preocupar a Baroja pese a que Ramsden $(1982 b, 21)$ sostiene que «Baroja was much concerned with chronological verisimilitude in the 1903-1904 revision ${ }^{27} \gg$. Este crítico (1982a y 1982b) postula que Baroja tuvo en cuenta la época en la que se desarrolla Aurora roja a la hora de ampliar y redistribuir el contenido de $L a$ busca inicial en dos libros. De esta forma, la adaptación de la época contemporánea a un pasado que debía abarcar quince años, supuso un inconveniente histórico que el escritor intentó sortear como pudo. Ramsden da como prueba de esta actitud el expurgo cronológico que hizo en algunos pasajes en ese paso de una versión a otra. Así, menciona la eliminación de posibles anacronismos, fácilmente asimilables, como el derribo del palacio de Osuna y la supresión de

25 «Por esta época [1902], o un poco antes, comencé yo mis preparativos para escribir La busca» (Baroja 1997a, 837).

26 Traduzco: «El objetivo general de Baroja en la revisión de 1903-1904 parece haber sido mantener, e incluso aumentar, la verosimilitud cronológica general del trabajo».

27 Traduzco: «Baroja estaba muy preocupado por la verosimilitud cronológica en la revisión de 1903 a 1904». Ramsden incide en esta idea: «Baroja struggled hard with the chronological problems caused by the addition of Aurora roja and changed several passages where there would otherwise have been a glaring anachronism in the revised version» [Baroja luchó duramente contra los problemas cronológicos causados por la adición de Aurora roja y cambió varios pasajes que, de lo contrario, se hubiesen considerado flagrantes anacronismos en la versión revisada] (1982a, 25). 
«automóviles» en «[c]ruzaban [...] coches, automóviles, caballos, carros» (Baroja 1903, 30). A estos hay que sumar la elisión de la referencia al campanil de Atocha, no aludida por este estudioso ${ }^{28}$. Otros, no obstante, observa que los tuvo que dejar por su importancia en la novela como el asfaltado de la puerta del Sol o el episodio del repatriado. Sin embargo, no da una explicación de por qué mantiene las zarzuelas de la kermesse de la calle de Pasión.

Con todo, la realidad es que Baroja apenas modificó los acontecimientos y los sucesos narrados en la versión primitiva de La busca manteniendo el viaje de Manuel desde el apeadero de Soria, el crimen de la calle de Malasaña (o de la calle del Barquillo), el crimen de las Peñuelas, la Doctrina, don Tancredo, las zarzuelas de la kermesse, la mención del automóvil en la historia de don Alonso, el cuartel de María Cristina, el asfaltado de la Puerta del Sol y el derribo de las cuevas de la Montaña. E, incluso, al ampliar el contenido de esta para dar cabida a los dos primeros libros de la trilogía, incurrió en un mayor número de referencias contemporáneas a su escritura. Porque Baroja no pretendió escribir con la exhaustividad de un historiador. El mismo Ramsden (1982a, 27) apunta que «[c]hronology is forced on Baroja by the form of his novel, but he is not a historical novelist. His vision is basically present: responses to the world in which he himself was immersed ${ }^{29} \gg$. Por este motivo, resultaría más que improbable que Baroja se preocupara por acontecimientos más propios de la investigación de un historiador y que resultan ilógicos considerando La busca de 1904 enmarcada en los años que establecen los críticos. Lugares mantenidos en la versión de 1904 como el apeadero de Soria, el edificio donde se imparte la Doctrina o el cuartel de María Cristina pueden calificarse como anacronismos justificables. Sin embargo, otros no tendrían sentido. Así, las zarzuelas de la kermesse podrían haberse cambiado, fácilmente,

${ }^{28}$ Es cierto que las referencias al palacio de Osuna y al campanil de Atocha son muy reveladoras del tiempo de la acción novelesca y no he llegado a una conclusión del motivo de su eliminación. Sin embargo, no tienen, por sí solas, suficiente fuerza como para desdecir al resto de referencias contemporáneas. Por otro lado, la supresión de «automóviles» puede deberse a la consideración de Baroja de lo inadecuado de este término relativo al Madrid de 1903 ya que no sería habitual encontrarse con uno de ellos. Así, por ejemplo, Francisco Flores García en $A B C$ del 29 de septiembre de 1903 declara que: «Al menos en España, nadie emplea el automóvil como auxiliar de ninguna industria, ni se alquila a tanto la hora o la carrera, y solo montan en él por mero sport sus dueños, seres privilegiados que, ante todo, se proponen rendir culto a la moda dominante desafiando el peligro a cara descubierta y demostrando un valor rayano de la temeridad» («Los caballos de punto. Crónica ligera», 4). En cambio, Baroja no quitó la alusión en boca de don Alonso - «hacía fa..., fa..., fa..., como un automóvil» (Baroja 1998, 151)-que se menciona en la historia que cuenta a los habitantes del Corralón y no tiene repercusión física en la realidad madrileña. Ramsden $(1982 a, 20)$ considera esta alusión como un anacronismo al situarlo en 1886 en La busca de 1904 ya que es difícil que, en la década de los 80, los oyentes de don Alonso dieran como normal esa referencia al automóvil.

29 Traduzco: «La cronología resulta forzada en Baroja por la forma de sus novelas, ya que no es un novelista histórico. Su visión es, básicamente, contemporánea: responde al mundo en el que él mismo estuvo inmerso». 
por otras. Precisamente, Baroja conocía perfectamente la época en la que se empezó a representar Los cocineros ya que en sus memorias recuerda que «[h]acia 1897 o 1898 vinieron mi madre y mi hermana Carmen de San Sebastián. [...] Mi madre y mi hermana vieron las zarzuelas que se representaban en Madrid, y, entre ellas, una que se hacía en el teatro Eslava, titulada Los cocineros» (Baroja 1997a, 639). Además, la adición de más «anacronismos» no hace sino corroborar el desapego barojiano a las referencias temporales que actúan únicamente como marcadores de una evolución biológica de los personajes pero, en ningún caso, histórica ${ }^{30}$.

Pero, antes de desgranar estos nuevos marcadores históricos, se hace necesario discutir el año que se ha tomado, generalmente, como inicio de La busca de acuerdo con la deducción de Beltrán de Heredia (1974), secundada por la autoridad de Alarcos (1982), y que alude al «famoso proceso de la calle Malasaña» (Baroja 1998, 78) como trasunto del crimen de Fuencarral. Baroja da suficientes pistas para que los lectores de aquella época reconocieran un suceso que quedó anclado en la memoria colectiva en 1888: el crimen de Luciana Borcino, una millonaria viuda de cincuenta años, que fue apuñalada y quemada con petróleo en su casa. Se culpó a su criada, Higinia Balaguer, a la que en 1890 se le aplicó el garrote vil.

Sin embargo, en este último caso, la inclusión, poco después, del crimen de las Peñuelas (Baroja 1998, 94) invalida la premisa impuesta por Beltrán de Heredia, pues lo mismo se podría deducir de este crimen enmarcado, como se ha indicado anteriormente, en 1902 y que, si bien no es tan conocido, no tiene por qué carecer de similar validez cronológica. Resulta, además, poco creíble que Baroja, al reescribir La busca, aprovechara providencialmente esta alusión al crimen de Fuencarral que, ya se ha dicho, había aparecido en el folletín de $E l$ Globo como el crimen de la calle del Barquillo, para apuntalar el año de 1888 como inicio de esta. Ciertamente, la mención velada al crimen de Fuencarral no deja de ser una novelización algo burlesca de este suceso tan manido que interesó sobremanera a la sociedad española. Esta novelización -que ficcionaliza la calle y los personajes- lo invalida para considerarse como un hecho objetivo con el que fechar la época histórica de la novela. En este aspecto, los demás crímenes que se entreveran en La busca y Mala hierba (fuera, evidentemente, de los acaecidos a los personajes barojianos) son reales ${ }^{31}$, así como los numerosos sucesos

${ }^{30}$ Como se ha mencionado previamente, críticos como Andrenio y Zeda vieron en la trilogía de 1904 el Madrid de comienzos de siglo. Por otro lado, Baroja tampoco mostró gran celo a la hora de intercalar los marcadores temporales (vid. Alarcos 1982, 47).

${ }^{31}$ En Mala hierba, Baroja alude a otros dos crímenes: en el primero, se refiere claramente al crimen de Fuencarral cuando la Flora «recordó que de chica había visto la ejecución de la Higinia» (Baroja 1998, 398) y describe cómo fue dicha ejecución. El propio Baroja vio el ajusticiamiento de la criada, según relata en «Verdugos y ajusticiados» de Vitrina pintoresca (1935); en el segundo, se puntualiza otro que causó gran revuelo a finales de 1890: «Al pasar por la calle del Ferrocarril, el sereno señaló el sitio donde habían encontrado descuartizada a la mujer del saco» (Baroja 1998, 425). Y, efectivamente, el 18 de noviembre de 1890 dedicaban los periódicos gran espacio al hallazgo del cuerpo mutilado de una mujer en la calle del Ferrocarril. 
históricos mencionados en Aurora roja y que tienen que ver, en su mayor parte, con el anarquismo ${ }^{32}$.

\subsubsection{Material añadido en 1904}

\section{La zarzuela El bateo}

Esta zarzuela se sugiere en la alusión a la letra con la que se burla un golfo de una anciana que había acudido a la Doctrina a por limosna. El golfo, ante la avaricia de esta, exclama la frase: "Ya la han tañado a usted, agüela [...]. Usted lo que es es una ansiosa» (Baroja 1998, 108) e, inmediatamente, se encarga el narrador de especificar que «la frase [...] procedía de una zarzuela» (Baroja 1998, 108). Y, en efecto, la frase está tomada del sainete lírico El bateo, con letra de Antonio Paso y Antonio Domínguez y música de Federico Chueca, estrenado el 7 de noviembre de 1901 en el Teatro de la Zarzuela. El argumento gira en torno al bateo (bautizo) del hijo de Lolo y Nieves y la intromisión de Pamplinas, antiguo novio de esta, que se atribuye su paternidad. El personaje que levanta más comicidad es el padrino, Wamba, anticlerical y anarquista que, ante un papeleo que debía efectuar la pareja al no estar casada y que suponía un desembolso de dinero, dice al cura: «A usté le he tañao yo, amigo; usté lo que es, es un ansioso» (Paso y Domínguez 1911, 30). La frase se hizo muy popular en aquella época ${ }^{33}$.

\section{El león de la zapatería}

También hay otro dato que remite a la realidad contemporánea de Baroja, en un pasaje que no existía en la versión seriada. La zapatería en la que trabaja Manuel se anuncia con el rótulo: «A la regeneración del calzado». Baroja, con evidente sorna, explica las connotaciones críticas de esta muestra:

El historiógrafo del porvenir seguramente encontrará en este letrero una prueba de lo extendido que estuvo en algunas épocas cierta idea de regeneración nacional, y no le asombrará que esa idea, que comenzó por querer reformar y regenerar la Constitución y la raza española, concluyera en la muestra de una tienda de un

\footnotetext{
A su lado, se encontraron dos sacos en los que fueron trasladados sus restos hasta allí. Hubo alguna confusión en la prensa con este crimen y el de una anciana encontrada en un saco en la calle de Fray Luis de León en abril de 1892 al que se le dio el nombre de «La mujer del saco».

32 Remito a la edición crítica de Aurora roja de J. M. Marín (2011), donde se desgranan muchas de las alusiones sobre el anarquismo.

33 Tañar: coloq. 'Conocer las cualidades o intenciones de alguien' (DLE $2014<\mathrm{https}$ :// dle.rae.es $>$ ). No he podido fechar, por otro lado, las dos letras de tangos que canta Encarna a Leandro (Baroja 1998, 140). La que comienza como «De las grandes locuras que hace el hombre» la menciona Baroja en «La canción callejera» de Intermedios (1931) enmarcándola en la década de 1890 (Baroja 1999a, 337-338).
} 
rincón de los barrios bajos, en donde lo único que se hacía era reformar y regenerar el calzado (Baroja 1998, 86).

Por tanto, se trata de un letrero cargado de ironía sobre la política regeneracionista española a raíz del desastre del 98 que, como señaló Senabre (1976), se personaliza en el político Joaquín Costa caricaturizado en el letrero de la zapatería de enfrente, «El león de la zapatería», en alusión a su apodo como «el león de Graus» ${ }^{34}$. Baroja compartió los ideales regeneracionistas junto con Azorín y Ramiro de Maeztu, formando el llamado grupo de «Los tres» y llegando a publicar un Manifesto en 1901 en el que expusieron sus teorías. Sin embargo, esta unión acabó siendo infructuosa y Baroja, desengañado de lo estéril de su intento, plasmó en Costa la inutilidad del regeneracionismo. En La busca, además, parodió al grupo de «Los tres» con «La sociedad de los Tres» compuesta por Manuel, el Bizco y Vidal, degradación muy similar a la de Costa. Baroja, de esta forma, ironiza con el resultado de la política regeneracionista encabezada por Costa que resultó improductiva y que el «historiógrafo del porvenir» tendría que buscar más allá de $1898^{35}$. Además, y como observa Estruch (Baroja 2012, 53, nota 4): «Los comentarios críticos fueron añadidos en la edición de 1904, cuando Baroja ya había abandonado la dirección interina de El Globo, periódico partidario de Costa».

\section{Rosita Montañés}

Propio de la ficción, se da un dato revelador acerca de la época en la que se desarrolla La busca y que no estaba en la versión de 1903. Roberto Hasting pregunta a don Alonso, el Hombre-boa, por una volatinera llamada Rosita Buenavida y su edad. Este recuerda a otra Rosita, de apellido Montañés, que era bailarina, y que «fui a París el sesenta y ocho [...]. A los cuatro meses, [fui] a América, y dos o tres años después conocía a Rosita, que entonces tendría veinticinco a treinta» (Baroja 1998, 129; en las demás ediciones que he consultado, excepto en Biblioteca Nueva, «veinticinco o treinta»). Ante esto, Roberto calcula que «la Rosita que usted dice tendría ahora sesenta y tantos» (Baroja 1998, 129).

\footnotetext{
${ }^{34}$ Además, Baroja acude a la realidad para hacer más jocosa esta mención. En La busca se describe el rótulo como: «Un hermoso león amarillo con cara de hombre y melena encrespada, puesto en pie, tenía entre las garras delanteras una bota, al parecer, de charol. Debajo de la pintura se leía lo siguiente: "La romperás, pero no la descoserás"» (Baroja 1998, 87). En «Epigrafía Callejera» de Vitrina pintoresca, Baroja nos dice que: «En una zapatería de la calle Mayor y en otra del Rastro había pintado un león desgarrando una bota. En la leyenda decía: "La romperás, pero no la descoserás"» (Baroja 1999a, 1117). Esta leyenda fue muy conocida y se utilizó en zapaterías de diferentes lugares. En el periódico La Gran Vía («Muestras y rótulos», 27 de agosto de 1893), incluso, se da cuenta del letrero en la localidad francesa de Agén con un dibujo del mismo.

35 Juan Arbó (1963) estudió detenidamente el grupo de «Los tres» y ya señaló la burla regeneracionista en La busca.
} 
Alarcos, atendiendo a sus cálculos, refiere que «[1]a escena [...] se situaría [...] por lo menos en 1900, mientras en la narración novelística se está produciendo en 1889» $(1982,49)$.

Reverte

Ramsden (1982a, 21), muy atinadamente, indica que en el nombre del perro del señor Custodio, Reverte, gravita la figura del torero Antonio Reverte. Para este estudioso se trata de un anacronismo, ya que tomó la alternativa en septiembre de 1891. Seguramente, Baroja añadió este apellido al perro en la versión de 1904 al conocer la noticia de la muerte del diestro, el 13 de septiembre de 1903.

\section{El parlamento del Conejo}

El Conejo es un irreverente trapero que vende a voz en grito cachivaches de todo tipo. En una ocasión le cuenta a Manuel que suele ser detenido debido a exclamaciones como esta: «Porque el otro día me puse a gritar en la calle: ¡Aire, quién compra el paraguas de Sagasta, el sombrero de Krüger, el orinal del Papa, una lavativa que se le ha perdido a una monja cuando estaba hablando con el sacristán!...» (Baroja 2010a, 439) ${ }^{36}$.

Las palabras que menciona el trapero destilan ironía e irreverencia por todos lados siendo un guiño a los lectores de la época.

\section{a) El paraguas de Sagasta}

El paraguas de Sagasta hace alusión al ya aludido Práxedes Mateo Sagasta y a la manera de gestionar las crisis gubernamentales sin que le tocaran, escondido en su metafórico paraguas. Así, en El Imparcial («Miscelánea política», 17 de marzo de 1883, 1) se lee que: «[C]uando descargó el chaparrón de enero, [Sagasta] hizo lo mismo. Abrir el paraguas, y echando adelante, dejar que se mojaran los Sres. Camacho, González, Albareda y León y Castillo». La metáfora, muy conocida, se vinculó en muchas ocasiones a Sagasta, según he podido comprobar en diferentes momentos y en diferentes periódicos. Por ejemplo, en El Liberal («A vuela pluma», 21 de enero de 1890,1$)$ se señala que para la «próxima tempestad

${ }^{36}$ En la edición de Biblioteca Nueva y de Círculo de Lectores se suprime «el orinal del Papa» (Baroja 1946, 362 y Baroja 1998, 214). Esta eliminación ya fue mencionada por Prieto $(1980,299)$. ;Aire!: parece que se trata de una exclamación con la que los vendedores llamaban la atención. «A tres, a tres perras chicas libros...! -vocea el vendedor primero. El segundo le contesta: -¡Aire, aire...! ¡Animarse!» («Al aire libre. ¡A tres perras chicas libros...!», Blanco y Negro, 16 de julio de 1911, 35). 
parlamentaria [...] [b]ien de tiempo le han dado para que compre un paraguas a su gusto»; y, algo más de un año después, en La República («Crónica parlamentaria», 8 de abril de 1891,2$)$ se recurre, de nuevo, al mismo símbolo: «Rectifica el Sr. Romero Robledo [...] anunciando al Sr. Sagasta que, cuando tenga conocimiento de que se aproxima la nube, se lo avisará para que abra el paraguas». También fue una referencia muy aprovechada por caricaturistas de periódicos como La Correspondencia de España («Ya empieza a enterarse», 24 de abril de 1894), El Liberal («Hoy se abren las cortes», 19 de noviembre de 1902) (Fig. 3), Don Quijote (28 noviembre de 1902) o La Correspondencia Militar («La nube», 22 de junio de 1901; «¡Agua va!», 5 de junio de 1902; «Temporal político», 5 de noviembre de 1902). La alusión de Baroja se entiende, como se mencionará más adelante, a causa de la muerte de Sagasta, en enero de 1903.

\section{b) Paul Kruger}

En España, la figura de Paul Kruger -o Krüger- (1825-1904) con sombrero de copa alta y larga sotabarba blanca se hizo famosa a través de los periódicos que narraban con inusitado interés la Segunda Guerra Anglo-Bóer (18991902) entre Gran Bretaña y los sudafricanos de origen holandés (bóeres) que vivían en las repúblicas independientes del Transvaal y del Estado Libre de Orange. Kruger, presidente de la República de Transvaal (1883-1900), desarrolló una fuerte oposición a los intereses expansionistas de los ingleses, convirtiéndose en un símbolo de la lucha contra el imperialismo. El 31 de mayo de 1902 se declaró la soberanía británica por el Tratado de Vereeniging. Baroja, Valle-Inclán, Maeztu y Camilo Bargiela estuvieron a punto de unir sus plumas para escribir Los misterios de Transvaal, novela por entregas que, al final, solo llevó a cabo Maeztu con el título de La guerra del Transvaal y los misterios de la banca de Londres de tendencia probóer y en la que dice Baroja que colaboró «aunque muy poco» (Baroja 1997a, 816).

\section{c) El orinal del Papa}

En este caso, el Conejo parece referirse al papa León XIII, muerto en julio de 1903 y que, en su larga enfermedad, tuvo una persistente disentería. Sirva de ejemplo un texto de La Dinastía («Por telégrafo y teléfono. Extranjero. Del Vaticano», 7 de junio de 1903, 3): «A pesar del empeño que en ocultarlo hay en el Vaticano sábese que se ha reducido la diarrea que hace seis meses padece León trece». Esta noticia apareció en muchos diarios durante cierto tiempo. Así, incluso, coincidió en la página donde se publicaba La busca en El Globo con el título «El Papa con disentería» el 6 de marzo de 1903. Estruch (Baroja 2012, 238, nota 2) sugiere que esta referencia proviene del dicho «Ser más serio que el orinal del Papa». No obstante, la mención de las dos alusiones a 
personajes de la sociedad de aquella época hace más viable la mención jocosa a la enfermedad del papa.

Los tres objetos, provenientes de estos importantes personajes, se desvirtúan, con gran ironía barojiana, en boca de un trapero que recoge objetos desgastados o inservibles: el legado de Sagasta, el fracasado intento de independencia de Krüger y la religión católica y su cabeza visible.

\section{Los embustes del Conejo: Garibaldi y Weyler}

Poco después del parlamento anterior, el Conejo lanza una serie de embustes a los que se encuentran con él que tienen que ver con personas muy conocidas de la época, como el borracho Garibaldi y el general Weyler -ya mencionado previamente al hablar del repatriado-.

Del primero refiere que en las Cambroneras, donde vivía, tuvo un encuentro con el obispo de Madrid-Alcalá que se murió al probar una taza de chocolate que le ofreció. Los lectores conocían de sobra la figura de este personaje que comenzó a popularizarse en la prensa a partir de 1900. Incluso, fue uno de los tipos estudiados en La mala vida en Madrid (1901) de Bernaldo de Quirós y Llanas de Aguilaniedo, al que calificaron como «alcoholista profesional» (1998, 99 y 101-103) (Fig. 4).

Por su parte, dice de Weyler que «al volver del campamento unas moscas se le han puesto en la cara y le han comido toda la oreja. Ha pasado por el puente de Segovia echando sangre» (Baroja 1998, 216). Baroja alude al campamento de Carabanchel, donde se realizaban prácticas para la instrucción de soldados y alumnos de las academias militares. Estaba en manos del Ministerio de la Guerra del que Weyler fue la cabeza visible en tres ocasiones, la primera de ellas entre marzo de 1901 y diciembre de 1902. Seguramente, iba con cierta frecuencia al campamento, pasando por el puente de Segovia. En La Época («Notas de última hora», 9 de octubre de 1901, 3) se da cuenta de su actividad en este lugar: «El ministro de la Guerra, a caballo y seguido de su Estado Mayor, ha inspeccionado los ejercicios de tiro que se hacen en el campamento de Carabanchel, regresando esta tarde a Madrid ${ }^{37}$.

\subsection{Mala hierba (1904)}

En Mala hierba también es posible encontrar algunas referencias que remiten a la época en la que escribió Baroja la trilogía. Al Asilo de las Delicias, la

\footnotetext{
${ }^{37}$ Se efectuaban en días señalados simulacros que trataban de emular las guerras, con la asistencia, incluso, de Alfonso XIII y, también, siendo «maniobras ordenadas por el ministro de la Guerra» («Actualidad española. El rey Alfonso XIII en las maniobras militares», Caras y Caretas [Buenos Aires], 15 de junio de 1901, 12).
} 
recogida de pobres al Cerro del Pimiento y la referencia al repatriado ya analizadas, se suman las de dos zarzuelas y el debut de La Chelito que ahondan en la adición de elementos más cercanos a la realidad en la que Baroja escribió la trilogía y no con afán historicista sino novelístico.

\section{Los sobrinos del capitán Grant}

Finalizando, según Alarcos, el quinto año de las peripecias de Manuel se relata que: «El día de Año Nuevo, [...] la baronesa, Kate y Manuel fueron al teatro de Apolo a ver Los sobrinos del capitán Grant» (Baroja 1998, 283). Estrenada el 25 de agosto de 1877 en el Teatro del Príncipe Alfonso, se convirtió, pronto, en un clásico de los escenarios en la época navideña. Que tenga constancia, en las dos últimas décadas del siglo XIX se representó en tres ocasiones el día 1 de enero en el Teatro Apolo: 1885, 1896 y 1898. Baroja, una vez más, no trata de adaptar su trilogía a una línea histórica revisada.

\section{La Chelito}

Como se ha indicado anteriormente, Alarcos $(1982,43)$ vio en el debut de Chuchita el del personaje real de La Chelito:

En Mala hierba se cuenta la inauguración del salón París, donde debuta como bailarina Chuchita, la hija de la Coronela. El mismo Baroja nos identifica ese personaje: «Algo de lo que se refiere a vidas de bailarinas depende del conocimiento que hicimos hace más de cuarenta años con la Chelito ${ }^{38} 》[\ldots]$ y cuenta cómo, tras el debut de esta «en un salón de la calle de la Montera», fue con unos amigos a felicitar a su padre, de igual manera que en la novela Manuel, Vidal y unos periodistas fueron a dar la enhorabuena al Coronel, padre de Chuchita. [E]l debut de la Chelito en el París-Salón de la calle de la Montera, a los catorce años, tendría lugar en 1900, puesto que la bailarina falleció a los setenta y tres años en noviembre de 1959 .

Aun así, al igual que con el crimen de Malasaña-Fuencarral, no se puede dar validez cronológica absoluta a este acontecimiento, ya que está novelado por Baroja ficcionalizando el nombre de la bailarina y muchas de sus circunstancias personales. Sin embargo, sirve para verificar su tendencia a escribir en esta trilogía desde el presente o el pasado más cercano, sea desde sus vivencias o inspirándose en sucesos periodísticos. Merece la pena mencionar, en este último caso, la inclusión en la novela del personaje de Roberto Hasting, que no estaba en la versión de 1903, y que relata a Manuel en La busca y Mala hierba sus desvelos por conseguir cobrar una herencia millonaria. Aunque hay una parte de la historia basada en un hecho real ocurrido a Baroja (Baroja

\footnotetext{
38 Baroja 1997a, 841.
} 
1997a, 364-365; Caro Baroja 1972, XVI-XVII), también tiene trazos de inspirarse en una intriga aparecida a finales de 1901 de la que se ocuparon mucho los diarios y que trataba de la lucha de Enrique Sackville por ser reconocido como hijo legítimo de Lionel Sackville, un rico lord inglés, y de Pepita Durán, una bailarina española, ya que estaba en juego un gran patrimonio y el título de lord. No es baladí que Andrenio, en su crítica a Mala hierba («Revista literaria. Mala hierba [novela], por Pío Baroja [La lucha por la vida]», El Imparcial, 29 de mayo de 1904, 5), ya lo propusiera como base de la historia de Baroja afirmando que: «Al trazar el tipo de Roberto Hasting, Baroja se ha inspirado, sin duda, en la realidad, acaso en el asunto Sakville [sic] [...]. Los periódicos hablaron mucho de esa novelesca historia, que se perdió luego en el papel sellado de la curia, y ahora resurge en las páginas de una novela» ${ }^{39}$.

\section{La Tempranica}

En el episodio del merendero de la señora Benita, los personajes cantan diversas canciones muy conocidas en la época. La única que he podido datar claramente es la perteneciente a la zarzuela La Tempranica-mencionada ya por el narrador y de la que se extracta una canción muy popular (Baroja 1998, 402)- que se estrenó en el Teatro de la Zarzuela el 19 de septiembre de 1900, con letra de Julián Romea y música de Gerónimo Giménez. En la versión de 1903 no aparece el nombre de la zarzuela ni la letra de la canción, pero sí se narra que Vidal «cantó otro [tango] burlesco con mucha gracia, cortando las frases para dar más intención y poniendo la mano en la boca de la guitarra, para detener a veces el sonido» (Baroja 1903, 56). Es la misma descripción que hace en Mala hierba para La Tempranica, por lo que Baroja no hizo más que

39 Recientemente, Estruch (Baroja 2012, 194, nota 11) ha mencionado el parecido con la historia de Sackville. A esta novelización de la realidad cercana, cabe añadir en Mala hierba (Baroja 1998, 257) -y en la versión inicial de La busca (Baroja 1903, 32)- la enumeración de actividades de la agencia de Bonifacio Mingote para lo que Baroja consultó las páginas de los anuncios de la prensa. En La Correspondencia de España fue habitual durante algunos números el de la Agencia comercial «La Ibérica», con muchas similitudes con lo expuesto por la empresa de Mingote desde «Se compraban» hasta «orinas» (así, por ejemplo, en la última página del número del 25 de marzo de 1903). El resto del anuncio también se hace eco de las persistentes proclamas hipotecarias o de préstamos monetarios, de los bajos precios que solían ofrecerse para atraer más la atención o de las amas de cría. También en Aurora roja, como indicó Alarcos, la huida de Juan del seminario se basa en un viaje que hizo a Soria en 1901 y del que salió el artículo «A orillas del Duero» (Alarcos 1982, 112). Y como el mismo Baroja reveló en «Las calles siniestras» de Vitrina pintoresca, literaturizó la historia en la que Manuel y Juan se encuentran con una criada y la convidan a cenar, seguramente en fecha cercana a la redacción de la trilogía: «La escena, algo transformada, la conté yo en una novela titulada Aurora roja» (1999a, 1129; Marín Martínez anotó esta alusión en su edición de Aurora roja [Baroja 2011, 241, nota 149]). 
añadir los datos para que el lector conociera la canción a la que se hacía referencia $y$, una vez más, se verifica que no existe ningún empeño de reescritura con afán historicista. En sus memorias, Baroja recuerda haber asistido al estreno de esta zarzuela junto con Valle-Inclán y otras personas, acabando todos en comisaría por causar alboroto (Baroja 1997a, 845-846) . $^{40}$.

\subsection{Aurora roja}

En la última novela de la trilogía, que apenas responde a la elaboración desde el folletón de $E l G l o b o^{41}$, Baroja evidencia la época histórica que quiere describir al referise a la coronación de Alfonso XIII en mayo de 1902, dos años

${ }^{40}$ Las otras canciones no he podido fecharlas con exactitud, pero aparecen también en La busca de 1903. Vidal canta «el tango del Espartero» (Baroja 1998, 402), compuesto a raíz de la muerte de este torero en 1894. Baroja en sus memorias reproduce este tango, y, pese a expresar una opinión muy desfavorable acerca de su letra, reconoce que «fue tan popular, que, a pesar de su vulgaridad, parece que vale la pena de recordarlo» (Baroja 1997a, 667-668); Calatrava, por su parte, entona un tango, circunscrito a la guerra de Cuba y que comienza como «Pinté a Matansa, confusa», calificado por el narrador como «una canción de insurrectos muy lánguida y triste» (Baroja 1998, 403). Años más tarde, de nuevo en sus memorias, Baroja volverá a transcribirla y la juzgará de forma positiva: «Este es un tango de insurrectos cubanos que está bien» $(1997 b, 686)$. Por último, la Justa tararea la letra de un tango para burlarse de la chata: «Eres más fea que un perro de presa, / y a presumida no hay quien te gane» (Baroja 1998, 401). No he encontrado mención anterior a Baroja sobre esta letra que, además, no parece que se corresponda con la original. Herrera y Sánchez $(1951,92)$ recoge así la canción: «Eres ma' chata que un perro de presa, / y a presumida no hay quien te gane». Y así debió de ser ya que la comparación era lugar común. El Diccionario de modismos $(1900,813)$ de Ramón Caballero recoge la entrada: «Nariz de perro de presa. Familiarmente, nariz chata y gruesa» [la cursiva señala la negrita original]. La tonadilla fue muy conocida y, aún en 1915, en la novela Amparo la plebeya, de Alberto Valero Martín, aparece tarareada por el personaje de la Loca que «cantó con un aire de tiento, pero sin entusiasmo: "Eres más chata q'un perro é presa"...» $(1915,11)$. Esta canción y la anteriormente citada «De las grandes locuras que hace el hombre» fueron consideradas por Baroja como misóginas en «Música callejera». Y, de nuevo, comete una incorrección en la primera al transcribir la letra: «Tienes cara de perro presa, / y a presumida no hay quien te gane» (Baroja 1997b, 686). No he conseguido identificar una habanera que canta Calatrava y que aparece descrita como «una canción cubana, triste, lánguida, que daba la nostalgia de un país tropical. Era una larga narración que evocaba los danzones de los negros, las noches espléndidas del trópico, el sol, la patria, la sangre de los soldados muertos, la bandera, que hace saltar las lágrimas a los ojos, el recuerdo de la derrota...» (Baroja 1998, 402-403). En todo caso, el «recuerdo de la derrota» se ha de entender en una realidad posterior a 1898.

${ }^{41}$ Baroja pasó a la mitad de Aurora Roja el último episodio de la versión seriada en el que capturan al Bizco $(1903,59)$. En él hay una mención sobre «los buenos tiempos en que se pasaba el vino de matute» (con el añadido final en Aurora Roja de «a carros» [Baroja 1998, 551]). Ramsden (1982c, 100-101) expone que Baroja lo agregó a la tercera parte de la trilogía para evitar un anacronismo con motivo del arrendamiento de consumos en Madrid en 1897 que perjudicaba se- 
después del encuentro de Manuel y Juan. Con todo, se trata de un dato más vistoso que refuerza la contemporaneidad de la obra. Además, se alude a las obras del Tercer Depósito, iniciadas en 1900, a la descripción de Le déshabillage impossible (1900) de Georges Méliès y a la presidencia de Sagasta, cuya última legislatura duró desde marzo de 1901 hasta diciembre de $1902^{42}$. En este sentido, todos los críticos coinciden en señalar la duración de esta novela de 1900 a 1902. De ahí que no existan los problemas anteriores con La busca y Mala hierba y no haya desajustes cronológicos en los sucesos mencionados.

Por otro lado, y como se ha reiterado, el tiempo de separación de Manuel y Juan mencionado al comienzo de la acción ${ }^{43}$, ha servido a los críticos para especular sobre la época histórica de las tres novelas. Visto lo expuesto en este artículo sobre La busca y Mala hierba, no deja de ser una maniobra de cuadrar el tiempo biológico de toda la trilogía con la que asumir la evolución característica de todos los personajes. Resulta evidente que Manuel toma en este libro un rol de cierta sensatez que va prosperando sobre su inmadurez pasada y que Baroja subraya con la referencia temporal de los quince años. Aun así, la época histórica sigue inamovible.

riamente a los matuteros. No dejaría de ser extraño que el novelista pudiera hilar tan fino en este fechado manteniendo, en cambio, otras referencias «anacrónicas» mucho más fáciles de datar.

${ }^{42}$ Las obras del Tercer Depósito del Canal de Isabel II dieron comienzo en 1900 pero se suspendieron el 7 de abril de 1905 debido a un grave accidente, ya que se derrumbó parte de la cubierta de hormigón causando gran número de muertos. Se consiguió terminar en 1915; por otro lado, en el cinematógrafo Salomón se proyectan varias películas que, seguramente, vio Baroja aunque los títulos no correspondan con los que hoy en día tienen: «Entre las películas del cinecromovidaograph había: La marcha de un tren, La escuela de natación, Un baile, La huelga, Los soldados en la parada, Maniobras de una escuadra, y, además, varios números fantásticos. Entre estos, los más notables eran uno de un señor que no puede desnudarse nunca, y otro de un hombre que roba y a quien le persiguen dos polizontes, y se hace invisible y se escapa de entre los dedos de sus perseguidores y se convierte en una bailarina y se ríe del juez y de los guardias» (Baroja 1998, 548). Las únicas películas que he podido documentar con cierta claridad son La marcha del tren y la del desnudo imposible. La primera parece corresponder con la famosa Arrivée d'un train à La Ciotat (1897) dirigida por Louis Lumière y la segunda a Le déshabillage impossible (1900) de Georges Méliès. Esta última, no obstante, fue copiada por algunas compañías en 1901 y 1902 (Balducci 2012, 141). En el catálogo Lumière existen varias películas que tienen cierto parecido con las otras mencionadas por su título por Baroja pero resulta complicado saber a cuál de ellas podría referirse. La que habla del hombre invisible tampoco la he localizado. Este motivo tuvo mucho recorrido y, por ejemplo, Segundo de Chomón en Le voleur invisible (1909) se acerca bastante a lo descrito en Aurora roja; por último, a Sagasta se le menciona cuando los anarquistas están preparando el atentado contra Alfonso XIII: «Figúrate tú, a los anarquistas qué nos importa que el rey viva o que no viva, que mande Sagasta o cualquier mamarracho de los republicanos» (Baroja 1998, 614).

${ }_{43}$ Manuel dice a Juan al principio del libro que «hace ya quince años que no nos hemos visto» (Baroja 1998, 459). 


\section{Conclusiones}

Aunque todos los críticos han asumido el periodo de 1885 o 1888 hasta 1902 como el marco histórico de la acción de La lucha por la vida, un estudio de los acontecimientos y personajes a los que se refiere Baroja hace indicar que la trilogía se desenvuelve a comienzos del siglo XX.

El tiempo interno del relato es elástico, flexible e impreciso, algo propio de un novelista y no de un historiador. Se trata de un tiempo que se apoya, ocasionalmente, en una concatenación de dichos, hechos y lugares de la época que dan sensación de inmediatez y apuntan a un momento histórico muy próximo a la redacción y publicación de la trilogía donde el tiempo de escritura coincide con el tempo interno de las novelas.

La crítica ha buscado fijar una cronología objetiva, calendárica, pero resulta afuncional para la comprensión global de la trilogía ya que el paso de los días, únicamente, sirve para legitimar el desarrollo biológico de los personajes.

Si bien en Aurora roja se cita un dato preciso y muy conocido como la coronación de Alfonso XIII, piedra angular de los razonamientos de los críticos sobre la horquilla que abarca la trilogía, unida al tiempo de separación de Manuel y Juan, no por ello las dos novelas anteriores se han de supeditar a esto ya que, igualmente, poseen sucesos de semejante índole.

Además, los intentos de amoldar unos pocos sucesos históricos para justificar un periodo de tiempo no son, además, exactos. Todos los estudiosos se han encontrado con lo que han considerado unos pocos anacronismos y los han aceptado al considerarlos descuidos de Baroja al abordar una cronología extensa. Sin embargo, los datos aportados en este artículo demuestran que, si se aceptara el fechado tradicional, el anacronismo sería absoluto ya que no hay ningún factor histórico que remita a una época anterior.

En este sentido, algunos de los acontecimientos históricos fechables reseñados por la crítica se basan en teorías poco consistentes. Así, tanto el crimen de Malasaña (asimilado, generalmente, como el comienzo de La busca) como el debut de Chuchita no deberían contarse como marcadores absolutos de un periodo concreto de tiempo ya que están ficcionados por Baroja. Y más cuando hay suficientes datos objetivos que ayudan a delimitar el Madrid que retrata la trilogía.

De hecho, Baroja se limitó a ampliar y reestructurar la primera versión de La busca, publicada en El Globo en 1903, y que estaba ambientada en los inicios del nuevo siglo, y de la que surgieron La busca y Mala hierba tal y como se conocen a partir de 1904, y a las que se sumó Aurora roja. En esa reescritura de la versión seriada, Baroja no buscó ningún tipo de verosimilitud cronológica como demuestra el mantenimiento de casi todos los materiales de 1903 y la adición de otros nuevos que dialogan con la misma realidad. 
De esta forma, el lector de la época asumió la trilogía como contemporánea, reconociendo los lugares aludidos por Baroja. Estos habían sido antes inmortalizados en las crónicas periodísticas que, desde algunos años atrás, ya daban cabida al mundo del hampa madrileño no solo para mostrar una cara desconocida de la capital, sino para alertar de los peligros de su crecimiento.

Es admitible que Baroja desconociera varios datos como las alusiones de ciertos edificios que no concuerdan con el fechado clásico (el apeadero de Soria, el edificio de la Doctrina, el cuartel de María Cristina o el Asilo de las Delicias). Sin embargo, se hace difícil suponer que, si quería dar veracidad cronológica a la trilogía, mantuviera o añadiera material que desvirtuaba claramente su empeño y que era fácilmente fechable por Baroja sin acudir a ningún tipo de documentación histórica (don Tancredo, las zarzuelas de la kermese, Rosita Montañés, los parlamentos del Conejo, el derribo de las cuevas de la Montaña o la zarzuela La Tempranica).

Por tanto, el fechado de la trilogía se mantiene en un mismo marco histórico que se mueve constantemente -y no de forma lineal- entre $1900 \mathrm{y}$ 1903, creando una paradoja que se muestra en continua incongruencia con el marco temporal que se ve supeditado al estatismo histórico y cronológico.

\section{ANEXO}

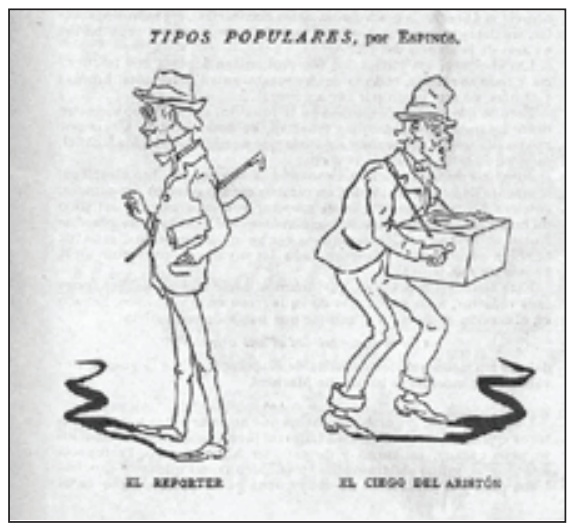

Figura 1. El reporter se convirtió en una figura habitual de las calles madrileñas («Tipos populares», Madrid Cómico, 17 de mayo de 1902, 157). Fuente: Biblioteca Virtual de Prensa Histórica del Ministerio de Cultura y Deporte de España.

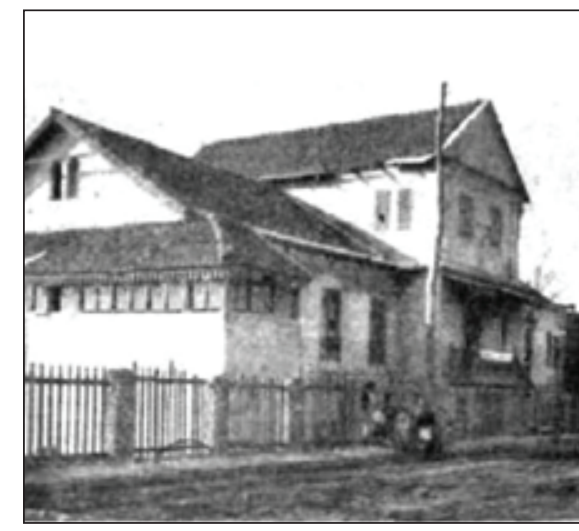

Figura 2. El Asilo del Sur con ese «aspecto de chalet suizo» del que habla Baroja («El frío y los pobres», Alrededor del Mundo, 2 de enero de 1902, 7). Fuente: Hemeroteca Digital. Biblioteca Nacional de España. 


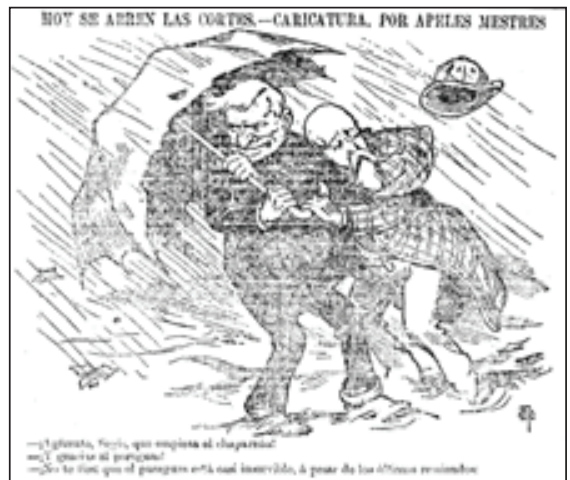

Figura 3. Caricaturizado por Apeles Mestres, Sagasta se protege con un paraguas, junto a Segismundo Moret, de un «chaparrón» político («Hoy se abren las Cortes», El Liberal, 19 de noviembre de 1902,1$)$.

Fuente: Hemeroteca Digital. Biblioteca Nacional de España.

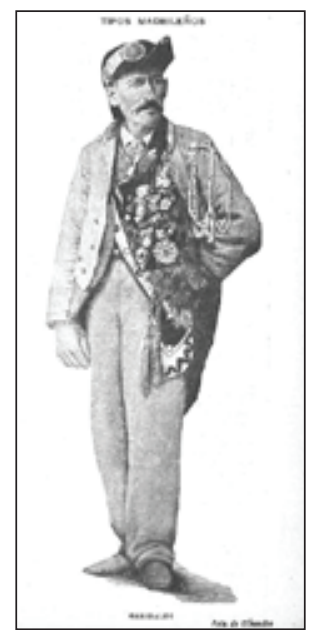

FIGURA 4. Con su sombrero apuntado y sus condecoraciones falsas en el chaqué, Garibaldi (apodo tomado del célebre militar italiano) fue el borracho más famoso de Madrid («Tipos madrileños. Garibaldi», Nuevo Mundo, 12 de diciembre de 1900, 8). Fuente: Hemeroteca

Digital. Biblioteca Nacional de España.

\section{FueNTES}

Baroja, Pío. 1903. La busca. El Globo, 4 de marzo-29 de mayo, 1-59.

Baroja, Pío. 1946. Obras completas I. Madrid: Biblioteca Nueva.

Baroja, Pío. 1972. La busca. Madrid: Caro Raggio, Editor.

Baroja, Pío. 1997a. Desde la última vuelta del camino I. Memorias: Obras completas I. Editado por José-Carlos Mainer. Barcelona: Círculo de Lectores.

Baroja, Pío. 1997b. Desde la última vuelta del camino II. Memorias: Obras completas II. Editado por José-Carlos Mainer. Barcelona: Círculo de Lectores.

Baroja, Pío. 1998. Trilogías II. Obras completas VI. Editado por José-Carlos Mainer. Barcelona: Círculo de Lectores.

Baroja, Pío. 1999a. Ensayos II. Obras completas XIV. Editado por José-Carlos Mainer. Barcelona: Círculo de Lectores.

Baroja, Pío. 1999b. Obra dispersa y epistolario. Obras completas XVI. Editado por JoséCarlos Mainer. Barcelona: Círculo de Lectores.

Baroja. Pío. 2010a. La busca. Editado por Juan María Marín Martínez. Madrid: Cátedra.

Baroja. Pío. 2010b. Mala hierba. Editado por Juan María Marín Martínez. Madrid: Cátedra. Baroja. Pío. 2011. Aurora roja. Editado por Juan María Marín Martínez. Madrid: Cátedra. Baroja, Pío. 2012. La busca. Editado por Joan Estruch. Barcelona: Vicens Vives.

Caro Baroja, Julio. 1972. «Prólogo». Pío Baroja, La busca. Madrid: Caro Raggio.

Estruch, Joan. 2012. «Introducción». Pío Baroja, La busca. Barcelona: Vicens Vives. 


\section{BIBLIOGRAFÍA CITADA}

Alarcos Llorach, Emilio. 1982. Anatomía de "La lucha por la vida». Madrid: Castalia.

Balducci, Anthony. 2012. The funny parts. A history of film comedy routines and gags. Carolina del Norte: McFarland \& Company.

Beltrán de Heredia, Pablo. 1974. «Regeneracionismo noventayochista en La lucha por la vida». En Pío Baroja, ed. Javier Martínez Palacio, 149-164. Madrid: Taurus.

Bernaldo de Quirós, Constancio y José María Llanas y Aguilaniedo. 1998. La mala vida en Madrid. Estudio psicosociológico con dibujos y fotografías al natural. Editado por Justo Broto Salanova; intr. Luis Maristany del Rayo; pról. José Manuel Reverte Coma. Huesca: Instituto de Estudios Altoaragoneses - Egido Editorial.

Caballero, Ramón. 1900. Diccionario de modismos. Frases y metáforas. Prólogo de Eduardo Benot. Madrid: Librería de Antonino Romero.

Ceballos Viro, Alvaro. 2016. "No me vengas con cosas de zarzuela": la verbena de la Paloma barojiana». En La zarzuela y sus caminos. Del siglo XVII a la actualidad, ed. Tobias Brandenberger y Antje Dreyer, 237-257. Münster: LIT Verlag.

Herrera y Sánchez, Francisco. 1951. «The Dances and Coplas of Canto Flamenco». Philological Papers 8: 83-101.

Juan Arbó, Sebastià. 1963. Pío Baroja y su tiempo. Barcelona: Planeta.

Moral Ruíz, Carmen del. 1972. «Baroja y la guerra de Cuba». Ínsula 308-309: 11-12.

Moral Ruíz, Carmen del. 2001. El Madrid de Baroja. Madrid: Sílex.

Paso, Antonio y Antonio Domínguez. 1911. El bateo. Sainete en un acto. Dividido en cuatro cuadros, en prosa y verso, música de Federico Chueca. 5. ${ }^{\text {a }}$ ed. Madrid: R. Velasco, Impresor.

Pérez Galdós, Benito. 2001. Nazarín. Editado por Gregorio Torres Nebrera. Madrid: Castalia.

Prieto, Antonio. 1980. Coherencia y relevancia textual. De Berceo a Baroja. Madrid: Alhambra.

Puértolas, Soledad. 1971. El Madrid de «La lucha por la vida». Madrid: Helios.

Ramsden, Herbert. 1982a. La busca. Critical guides to spanish texts. Londres: Grant \& Cutler, Tamesis Books.

Ramsden, Herbert. 1982b. Pío Baroja: «La busca»1903 to «La busca» 1904. Durham: University.

Ramsden, Herbert. 1982c. «The pursuit of El Bizco: two versions». En Essays on narrative fiction in the Iberian Peninsula in honour of Frank Pierce, ed. R. B. Tate, 95-104. Oxford: The Dolphin Book.

Senabre Sempere, Ricardo. 1976. «Notas sobre la elaboración de La busca». Archivum: Revista de la Facultad de Filología 26: 391-401.

Valero Martín, Alberto. 1915. Amparo la plebeya. Ilustraciones de F. Mota. Los Contemporáneos 337.

Fecha de recepción: 15 de noviembre de 2018 .

Fecha de aceptación: 06 de marzo de 2019 
